\title{
Movilidad residencial y redistribución de la población metropolitana: los casos de Madrid y Barcelona
}

Jordi Bayona-i-Carrasco. Universitat de Barcelona, Barcelona, España. Isabel Pujadas-i-Rúbies. Universitat de Barcelona, Barcelona, España.

RESUMEN | En las últimas décadas, los movimientos migratorios internos en las dos mayores áreas metropolitanas españolas (Madrid y Barcelona) han aumentado considerablemente, triplicando la intensidad de finales de los años ochenta. El proceso de desconcentración urbano, primero, y la incorporación de los extranjeros a estos flujos más tarde, son los motores de este intenso crecimiento, que presenta signos de estancamiento e incluso descenso durante los últimos años, como consecuencia de la crisis económica. La comparación de las dinámicas migratorias a partir del análisis de las Estadísticas de Variaciones Residenciales nos indica, en ambos casos, que las ciudades más densas y pobladas pierden población en dirección hacia las periferias metropolitanas, con municipios de menor tamańo. La movilidad residencial de la población se erige como el instrumento más importante en la redistribución de la población a escala metropolitana.

PALABRAS ClAVE | áreas metropolitanas, metropolización, migración.

ABSTRACT | During the last decades an increase of internal migration dynamics had been observed in the two main Spanish Metropolitan Areas, Madrid and Barcelona, with values three times higher than those observed in the 1980s. Two reasons explain this evolution: the urban deconcentration process, and, during the last decade, the foreigner's incorporation to residential mobility. Recently, stagnation or even decrease signs have been observed as a consequence of the recent economic crisis. Through the comparison of internal migratory dynamics using Residential Variation Statistics data, we observe similar patterns in both cases, where most dense and populated cities have lost population, whereas outlying and low populated municipalities have received internal migrants. Residential mobility is the most important instrument in the redistribution process of population at metropolitan level.

KEY WORDS | metropolitan areas, metropolization, migration.

Recibido el 2 de diciembre de 2011, aprobado el 15 de agosto de 2012.

E-mail: Jordi Bayona-i-Carrasco, jordibayona@ub.edu | Isabel Pujadas-i-Rúbies, ipujadas@ub.edu

Este artículo forma parte de dos proyectos financiados por el Plan Nacional de I+D del Ministerio de Ciencia e Innovación: "Estrategias residenciales y modelos urbanos en la RMB" (Cso2010-22117-C02-02), dirigido por la Dra. Cristina López; y "Las nuevas ciudades espańolas. El impacto espacial de las dinámicas demográficas recientes en las grandes áreas urbanas españolas en un contexto de crisis” (cso2011-24680), dirigido por la Dra. Isabel Pujadas. Isabel Pujadas es catedrática del Departament de Geografia Humana de la Universitat de Barcelona y coordinadora del Grupo de Investigación “Territori, Població i Ciutadania” (2009-SGR01086), reconocido por la Generalitat de Catalunya. Jordi Bayona es profesor asociado en el mismo Departamento. 


\section{Introducción}

El proceso de dispersión de la población metropolitana en España ha avanzado de forma continua durante los últimos años a lo largo de la mayoría de las grandes áreas metropolitanas españolas, proceso que se encuentra especialmente consolidado en las metrópolis más pobladas: Madrid y Barcelona. En esta dinámica, las migraciones internas de la población desempeńan un papel muy destacado, constituyendo uno de los elementos más importantes en las transformaciones territoriales observadas.

El objetivo de este trabajo es dar cuenta de la evolución y las características de la movilidad residencial registrada en las regiones metropolitanas de Madrid (Comunidad Autónoma de Madrid, CAM) y Barcelona (Región Metropolitana de Barcelona, RMB). Por "movilidad residencial" entendemos aquellas migraciones entre municipios con origen y destino dentro de una misma región metropolitana. El estudio se centra en las características demográficas de los migrantes, así como en las consecuencias territoriales de estos procesos migratorios sobre los espacios de origen y destino, y abarca el periodo comprendido entre 1988 y 2009.

Las migraciones residenciales en las dos mayores regiones metropolitanas espańolas han experimentado en las últimas décadas un aumento importante, tanto en volumen como en intensidad, propiciando una fuerte redistribución de la población en el territorio metropolitano. Esta movilidad intrametropolitana es la principal causa tanto del intenso proceso de suburbanización experimentado en las regiones bajo estudio (Champion, 2001), como de la pérdida de población de la ciudad central en dirección a las periferias metropolitanas, dinámica que paulatinamente se ha extendido a las ciudades más densamente pobladas. La irrupción de la inmigración internacional durante la última década ha ańadido mayor complejidad a este proceso, ya que ha revertido el decrecimiento de las áreas centrales, que vuelven a recuperar población, al mismo tiempo que siguen aumentando los desplazamientos metropolitanos, en parte por la progresiva incorporación de los extranjeros en ellos. Esta nueva situación modifica las pautas territoriales precedentes con la aparición de nuevos espacios de asentamiento. A pesar de ello, el peso de las ciudades centrales sobre el conjunto metropolitano sigue disminuyendo.

Nuestra hipótesis de trabajo es la existencia de un proceso de dispersión urbana que avanza ininterrumpidamente. Se trata de una suburbanización residencial con una diversidad de tipologías urbanas que afecta a todos los territorios metropolitanos de Madrid y Barcelona y a todos los tamaños de población. La migración metropolitana adquiere diversos perfiles y combinaciones, desde la máxima expresión del "sprawl"en los municipios menos densificados con predominio de viviendas unifamiliares, hasta las ciudades de tamańo medio, que han sido las grandes receptoras de la migración metropolitana. La comparación entre Madrid y Barcelona nos mostrará las semejanzas en la evolución del proceso, teniendo en cuenta que parte de las divergencias en los comportamientos residenciales serán fruto de las diferentes estructuras urbanas de ambos territorios, marcados por el mayor carácter policéntrico de la RMB (Roca, Arellano \& Moix, 2011; Trullén \& Boix, 2003), en contraposición al monocentrismo y la macrocefalia que comparativamente aún impera en la cAM (Roca, Arellano \& Moix, 2011), a pesar del continuado proceso de descentralización. 


\section{Marco teórico}

En el marco de las migraciones internas, la movilidad residencial consiste en aquellos cambios de residencia producidos con origen y destino dentro de una misma área urbana, y que en principio no deben suponer una modificación total en los espacios de vida de los individuos. A pesar del cambio de residencia, los lugares de trabajo, ocio o consumo pueden mantenerse inalterados. Estos desplazamientos se encuentran estrechamente vinculados con el desarrollo del ciclo de vida de los individuos (Rossi, 1955; Courgeau, 1985), mayoritariamente en relación con la emancipación familiar y la formación de un nuevo hogar (Mulder \& Wagner, 1993), con su disolución (Feijten $\&$ van Ham, 2007), pero también con el aumento del tamańo de las familias relacionado con la fecundidad (Kulu, 2008). Los cambios en la estructura de los hogares y familias relacionados con la segunda transición demográfica (Van de Kaa, 1987; Lesthaeghe, 1995), que llevan a la disminución del tamaño medio de los hogares y a la diversificación de las formas de convivencia, estarán tras el aumento de la movilidad (López-Villanueva, Pujadas \& Bayona, 2011).

Existe también una estrecha conexión entre movilidad residencial y nuevas necesidades de vivienda, sea que estos nuevos requerimientos se encuentren relacionados con cambios en la estructura familiar o su tamańo, o con variaciones en el nivel de ingresos (Clark \& Withers, 2007; Clark \& Onaka, 1982; Bonvalet \& Fribourg, 1990). Otro factor determinante en la movilidad residencial es la tenencia de la vivienda, dándose una menor propensión a la movilidad entre aquellos que viven en propiedad (Courgeau, 1985; Módenes \& López-Colás, 2004). Además del propio ciclo de vida, la demanda y la oferta de viviendas se relacionan directamente con la localización del movimiento residencial, en especial en función de la tipología de la vivienda (como la localización de las unidades unifamiliares, por ejemplo).

En el caso espańol, y si consideramos los movimientos absolutos, el aumento reciente de las migraciones metropolitanas se relaciona con la emancipación familiar de las generaciones españolas con más efectivos, aquellas nacidas entre mediados de la década de los sesenta y mitades de los setenta, a pesar de que la movilidad de las generaciones más llenas acostumbra a presentar tasas menores y una migración a mayor edad (Pandit, 1997a; 1997b). En cambio, y al mismo tiempo, este crecimiento coincide con el amplio periodo de bonanza económica experimentado hasta el estallido de la actual crisis económica y financiera, situación en la que las tasas de migración en general se incrementan. Finalmente, la irrupción de la inmigración internacional, especialmente numerosa desde inicios del siglo XxI, es el tercer factor de importancia que incide sobre el crecimiento de las migraciones internas (Martí \& Ródenas, 2006), especialmente las metropolitanas (Bayona \& Gil-Alonso, 2012). Entre la población extranjera, fruto de un proceso reciente de inmigración internacional, las posibilidades de migrar de nuevo se multiplican, atendiendo a varias razones: i) por los aún escasos vínculos adquiridos con la comunidad de acogida, que facilita un nuevo desplazamiento; ii) por la inseguridad laboral de quienes se acaban de incorporar a un nuevo mercado de trabajo (Nogle, 1994), siendo los extranjeros más sensibles a los cambios de la situación económica

(Kritz \& Gurak, 2001); o iii) por el creciente conocimiento adquirido respecto del mercado laboral (Xu, 2011) o del mercado inmobiliario del país (Simon, 1998). 
Además, debemos considerar otros factores, como la continua mejora de las infraestructuras viarias que, por un lado, permiten una mayor movilidad habitual entre residencia y lugar de trabajo, pero que al mismo tiempo se correlacionan con las áreas de mayor crecimiento suburbano (García-López, 2012). A esta mejora se suman la deslocalización del empleo desde las grandes ciudades hacia sus periferias y la aparición de nuevas formas de vida, que comportan un deseo de mejora de la vivienda actual para acceder a viviendas unifamiliares (las cuales se encuentran situadas, y construidas, fuera de la ciudad central). En España, incluso el acceso a un primer hogar, mayoritariamente en propiedad, ha dado lugar a cambios de municipio y a la intensificación del proceso de suburbanización (Módenes, 1998; Cabré \& Módenes, 1997). La movilidad residencial tiene una importancia destacada en los procesos de transformación urbanos, por su peso en el crecimiento de los municipios, pero también por generar una selectividad demográfica y socioeconómica que interfiere en el resto de fenómenos demográficos (Módenes, 1998).

Por otro lado, la dinámica de crecimiento de las poblaciones metropolitanas ha estado estudiada a partir de la dicotomía centro-periferia, donde la ciudad compacta tradicional evoluciona hacia una ciudad cada vez más dispersa, con periferias más extensas y articuladas. Al respecto, Hall (1971) distingue cuatro etapas de crecimiento: centralización, descentralización relativa, descentralización absoluta y reurbanización. Van den Berg, Drewett, Klaasen, Rossi y Vijverber (1982) y Cheshire (1995) presentan nuevas versiones, con un modelo cíclico de urbanización a partir de cuatro fases (cada una de ellas subdividida en otras dos): urbanización, suburbanización, desurbanización y reurbanización. En el primer estadio, el centro metropolitano gana más población que la periferia; en el segundo periodo ocurre lo contrario, con un centro que pierde población, la cual se localiza en sus periferias; en una tercera etapa, el decrecimiento se produce tanto en el centro como en la periferia; finalmente, se da un proceso de reurbanización donde el centro recupera habitantes y sus periferias disminuyen el ritmo de decrecimiento. Kabisch y Haase (2011) someten este esquema teórico a una verificación a partir del desarrollo metropolitano europeo de las últimas décadas, con el resultado de que a partir de 2001 coinciden temporalmente varias etapas, y no la evolución sucesiva de cada una de ellas.

Respecto de la Región Metropolitana de Barcelona, numerosos estudios dan cuenta del proceso de suburbanización y crecimiento metropolitano desplegado en ella. Borja (2010) expone varias razones explicativas del extenso crecimiento metropolitano, entre las cuales destaca la falta de planificación territorial del espacio metropolitano, que facilita la expansión residencial y la fragmentación territorial, junto con una política que prioriza la construcción de infraestructuras viarias como puntos catalizadores de la extensión. Las diferencias de precio entre centro y periferia y la extensión de la vivienda unifamiliar, junto con la propagación del vehículo privado en el transporte y la facilidad de crédito inmobiliario durante la última década, acaban por facilitar el proceso. Este fue observado por Pujadas (2009) ya durante los noventa, cuando las migraciones metropolitanas se extendían por todo el territorio metropolitano. En el caso de Madrid, GarcíaPalomares y Pozo (2010) observan un importante incremento de los flujos, que Vinuesa (2009) atribuye en parte a la oferta de vivienda asequible para los jóvenes 
en la periferia, lo que lleva asociado un crecimiento de la movilidad cotidiana por motivo de estudio o trabajo, y la posibilidad de un aumento de la desigualdad social vía movilidad habitual. En ambos casos, estas dinámicas se ven reforzadas por un proceso de desconcentración de la actividad económica, además de la aparición de nuevos espacios de consumo y ocio metropolitanos (Méndez, 2001; Nel.lo, 2011; Miralles-Guash, 2011).

\section{Fuentes estadísticas y metodología}

Se han utilizado datos que provienen, en su mayoría, de dos fuentes estadísticas: el Padrón continuo de población (Instituto de Estadística de Cataluña, IDEsCAT) y la Estadística de Variaciones Residenciales (EVR) (Instituto Nacional de Estadística, INE, España). El Padrón continuo es el registro administrativo donde constan los vecinos de un municipio espańol. Gestionado por los ayuntamientos y comprobado por el Instituto Nacional de Estadística, aporta datos anuales a 1 de enero, y desde 1998 ofrece la población oficial de los municipios españoles y del conjunto del país. Las variables disponibles son pocas -el sexo y la edad de los individuos-, a las que se suman la nacionalidad y el país de nacimiento. Ambas fuentes se encuentran interrelacionadas, ya que la EVR recoge datos de las altas y bajas de población realizadas en el Padrón, con las mismas variables del municipio de origen y el de destino. Si bien los datos referidos a migraciones internacionales son discutibles, especialmente las bajas en relación con el extranjero, en cambio se considera que la cobertura de la movilidad interna en España es bastante aceptable. Existen dudas, en este sentido, sobre el momento de comunicar el cambio de municipio (que puede ser posterior a la fecha en que realmente se produce) y de falsos empadronamientos que generen, al mismo tiempo, una falsa movilidad, por motivos fiscales (por ejemplo, en relación con la desgravación fiscal de la segunda residencia), o de inscripción escolar. A pesar de estas dificultades, la ventaja de las EVR es que permiten conocer, anualmente, la evolución de la movilidad y sus pautas geográficas. Debido a las características de la fuente, la movilidad residencial a la que nos referimos en este trabajo queda delimitada a los cambios residenciales producidos entre municipios de una misma metrópoli, sin tener en cuenta aquellos cambios que se producen dentro de un mismo municipio (y que, en el caso de la ciudad de Barcelona, representan aproximadamente entre un 70 y un 80 por ciento de todos las migraciones metropolitanas con origen o destino a la ciudad central [Bayona \& Pujadas, 2010]).

El Padrón continuo, con datos disponibles desde el año 1998, se utilizará para calcular la población de referencia en las tasas utilizadas. Se ha empleado el tamańo del municipio (fijado en 1996) y la distancia a la ciudad central, entendiendo que son variables clave en los procesos de movilidad residencial, con pérdida de población en las ciudades más densas y pobladas y ganancia de habitantes en los municipios más periféricos. Con las Evr, y con datos entre 1988 (cuando se informatizan los datos) y 2009, únicamente se consideraron aquellos movimientos migratorios con origen y destino dentro de la propia metrópoli, a pesar de que algunos trabajos indiquen que la movilidad residencial pueda, en ambos casos, estar sobrepasando los límites utilizados (Pozo \& García-Palomares, 2009). 
En cuanto a las áreas analizadas, para Barcelona se utiliza la Región Metropolitana de Barcelona, que cuenta con 164 municipios y unos $3.200 \mathrm{~km}^{2}$, con 5,01 millones de residentes (2010). Es uno de los siete ámbitos definidos en el Pla Territorial General de Catalunya, con una definición que se remonta a la década de los sesenta (Esteban, 2003), y que se configura en numerosos estudios como la unidad de análisis metropolitana preferente. En el caso de Madrid, la delimitación territorial es más compleja, sin que exista un área formal que englobe la dinámica metropolitana de la capital. Es por esta razón que se emplea la Comunidad Autónoma de Madrid, que consiste de 178 municipios en aproximadamente $8.000 \mathrm{~km}^{2}$ y con 6,5 millones de habitantes.

Temporalmente, se han realizado dos subdivisiones del periodo 1988-2009, con la intención de observar los cambios ocurridos en el tiempo y comparar la evolución de los procesos de movilidad: i) en cinco etapas: 1988-1990, 1991-1995, 19962000, 2001-2005 y 2006-2009; y ii) las décadas 1991-2000 y 2001-2009.

Metodológicamente se utilizan las tasas de inmigración, emigración y migración neta, por distancia a la ciudad central y tamaño del municipio. Se representan también las tasas específicas por sexo, edad y nacionalidad. A escala municipal, se presentan además los orígenes principales y secundarios de los flujos migratorios, que permiten delimitar las áreas de atracción migratoria y observar la existencia de subsistemas migratorios. Para reforzar este análisis se utiliza el coeficiente de interacción ${ }^{1}$, siguiendo la metodología empleada por Roca y Moix (2005), basada en Smart (1974) y en Coombes, Green y Openshaw (1986). Este coeficiente identifica las áreas que mantienen una elevada interrelación, y es utilizado en la delimitación de áreas funcionales en estudios sobre mercados laborales.

\section{La evolución de la población: ciudades centrales y regiones metropolitanas}

En las últimas décadas, la evolución de la población en los municipios metropolitanos se caracteriza por la existencia de dos grandes etapas: un primer periodo de estancamiento de la población metropolitana y decrecimiento de las ciudades centrales, con una fuerte redistribución de la población vía movilidad residencial; y una segunda fase en que el impacto de la inmigración internacional repercute en el signo de crecimiento metropolitano, que vuelve otra vez a ser claramente positivo, así como en el de las ciudades centrales (que recuperan población), y donde las cuotas de movilidad aumentan hasta alcanzar un máximo, por la progresiva incorporación de los extranjeros a la movilidad residencial. Con anterioridad, el proceso de inmigración interior campo-ciudad espańol supuso un fuerte crecimiento de ambas urbes, que finalizó en la década de los setenta debido a la crisis económica, aunque la ciudad de Barcelona ya había dado muestras de estancamiento diez ańos antes, producto de la saturación urbanística de la ciudad.

1 El coeficiente de interacción es formulado como:

$$
\text { Coeficiente_d_Interacción }=\frac{M_{i j}{ }^{2}}{\left(\text { Salidas }_{i}\right) *\left(\text { Entradas }_{j}\right)}+\frac{M_{j}{ }^{2}}{\left(\text { Salidas }_{j}\right) *\left(\text { Entradas }_{i}\right)}
$$

y relaciona los flujos de entrada y salida entre el conjunto de municipios analizados. 
CUADro 1 | Evolución reciente de la población en Madrid, Barcelona y sus regiones metropolitanas, 1981-2010

\begin{tabular}{|c|c|c|c|c|c|c|c|}
\hline & 1981 & 1986 & 1991 & 1996 & 2001 & 2006 & 2010 \\
\hline Barcelona & 1.752 .627 & 1.701 .812 & 1.643 .542 & 1.508 .805 & 1.505 .325 & 1.605 .602 & 1.619 .337 \\
\hline RMB & 4.238 .876 & 4.229 .527 & 4.264 .422 & 4.228 .048 & 4.390 .413 & 4.841 .365 & 5.012 .961 \\
\hline$\%$ ciudad central & 41,3 & 40,2 & 38,5 & 35,7 & 34,3 & 33,2 & 32,3 \\
\hline Madrid & 3.158 .818 & 3.058 .182 & 3.010 .492 & 2.866 .850 & 2.957 .058 & 3.128 .600 & 3.273 .049 \\
\hline CAM & 4.687 .083 & 4.780 .572 & 4.947 .555 & 5.022 .289 & 5.372 .433 & 6.008 .183 & 6.458 .684 \\
\hline$\%$ ciudad central & 67,4 & 64,0 & 60,8 & 57,1 & 55,0 & 52,1 & 50,7 \\
\hline
\end{tabular}

Fuente instituto Nacional de estadística (ine), CENSo de i98 I y i99i, PAdrón de I986 y I996; Y PADRÓN CONTINUO 200I, 2006 Y 2010

Por encima de otros factores, la desconcentración urbana marca la evolución de la población en las dos metrópolis, con un centro metropolitano que pasa por etapas de pérdida de población y una periferia en continuo crecimiento. Como resultado, en los últimos treinta años las ciudades centrales pierden protagonismo: Barcelona pasa de representar el 41,3 por ciento de la población metropolitana en 1981 al 32,3 por ciento en 2010; Madrid pasa del 67,4 al 50,7 por ciento (Cuadro 1). En ambos casos, las décadas de los ochenta y noventa se caracterizan por la dinámica negativa de los centros, de la que surge primero Madrid (a finales de los noventa), ligeramente más tarde Barcelona. Entre mínimo y máximo, Barcelona pierde casi 250.000 residentes, por 290.000 en Madrid. En Barcelona el proceso es más intenso, ya que pierde el 14,1 por ciento de la población inicial, pérdida que es tan solo del 9,2 por ciento en la ciudad de Madrid. A partir del mínimo observado, Madrid recupera e incluso supera la población de 1981; Barcelona, en cambio, no alcanza la de 1991 y aún se sitúa lejos de su máximo.

FIGURA 1 | Evolución de la población entre centro y periferia metropolitanos, $1970-2010(1970=100)$
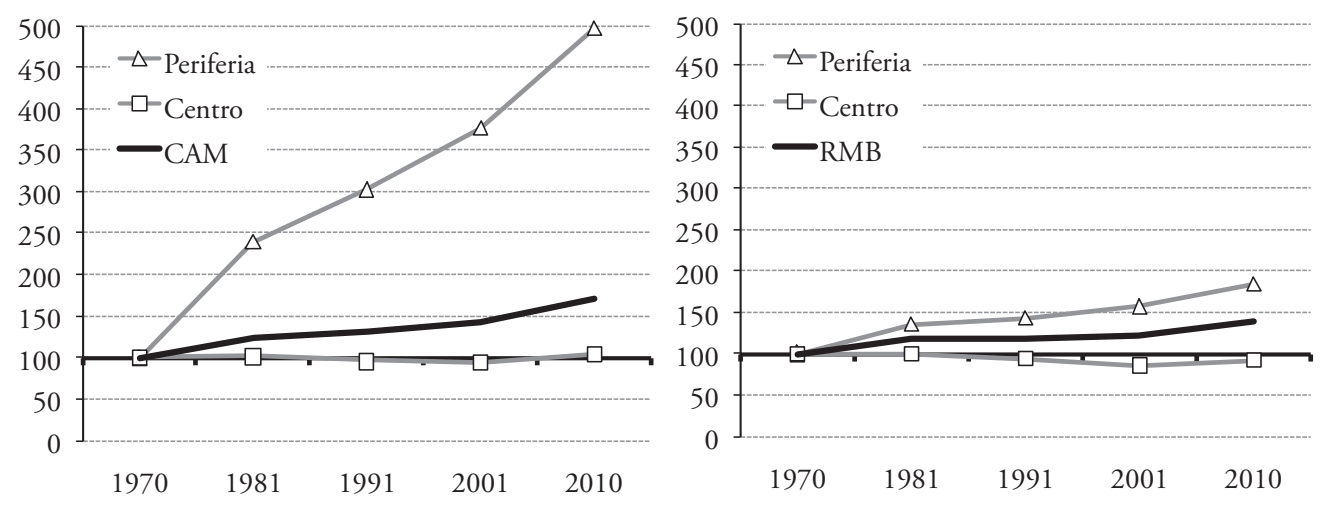

FUENTE CENSO DE I970, I98 I Y I99I; PADRÓN CONTINUO 200 I Y 20 IO (INE) 
En contraste, las regiones metropolitanas muestran menores semejanzas en su evolución. La CAM suma continuamente efectivos, para un total de 1.771 .601 nuevos habitantes partiendo de las cifras de 1981, mientras que en la RMB el crecimiento es menor (incluso negativo entre 1981 y 1996), para ganar finalmente 774.085 habitantes. El crecimiento relativo de la CAM entre 1981 y 2010 dobla el de la RMB $(37,8$ y 18,3 por ciento, respectivamente). A la vista de los primeros datos, se espera una dinámica de desconcentración mayor en la RMB por el mayor descenso de población de la ciudad central, aunque en la CAM el crecimiento de la periferia es mucho más intenso (Figura 1), y este proceso deberá significar un mayor impacto sobre el territorio.

Figura 2 | Tasa de crecimiento anual de los municipios de la CAM y la RMB, 1991-2010

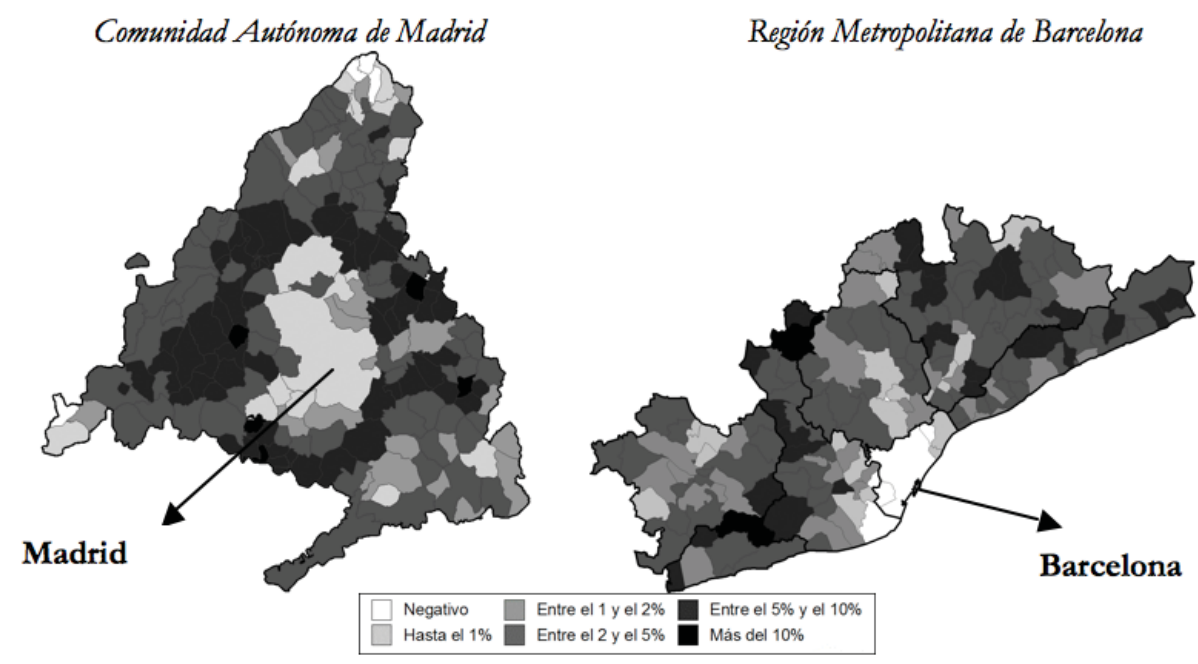

FUENTE CENSO DE I99I Y PADRÓN CONTINUO 2010 (INE)

A nivel municipal, el crecimiento en la CAM alcanza a la mayoría de municipios (Figura 2), a excepción de aquellos de la sierra norte, donde las dinámicas metropolitanas son aún poco importantes. La ciudad de Madrid se encuentra envuelta por municipios que han crecido a ritmos superiores al 5 por ciento anual (es decir, duplicando su población cada catorce ańos), mientras que las tasas superiores al 2 por ciento anual son generalizadas. Únicamente Madrid y algunos municipios colindantes crecen a un ritmo inferior, y a pesar de ello con incrementos positivos. En la RMB, en cambio, Barcelona y algunos de los municipios centrales pierden población. Las tasas superiores al 5 por ciento engloban un número menor de municipios y se encuentran más dispersas en el territorio, y dominan aquellos que crecen en un intervalo entre el 2 y el 5 por ciento anual. 


\section{La evolución de los movimientos migratorios}

El periodo 1988-2009 se caracteriza por un aumento continuo de las migraciones residenciales, que solo la reciente crisis económica consigue atenuar e incluso ligeramente revertir. El total de movimientos en ambas regiones metropolitanas es de similares dimensiones (Figura 3), con una evolución en el tiempo prácticamente idéntica $^{2}$. Si a finales de los ochenta las migraciones residenciales se situaban en torno a los 50.000 movimientos anuales, en sus puntos álgidos se sitúan alrededor de los 160.000. En 2006 (RMB) y 2007 (CAM) se observan los picos máximos; a partir de ese momento, la crisis significa un leve descenso, menor al que se podría esperar en relación con el brusco desplome del mercado inmobiliario, y un nuevo repunte en 2009, que los recientes datos de 2010 parecerían confirmar (datos que disponemos solo agregados). Existe un pequeño desfase entre ambas tendencias, lo que sitúa el número de migraciones de la CAM por encima de las de la RMB a partir de 2006, hecho que modifica la pauta observada desde inicios de los años noventa. $\mathrm{Al}$ calcular las tasas brutas de movilidad, encontramos que la movilidad residencial es ligeramente superior en la RMB durante todo el periodo, con un máximo del 33,1 por mil en 2005, para el 27,4 por mil del año 2006 en la CAM. Estos valores nos indican la existencia de un descenso de la movilidad residencial ligeramente anterior al estallido de la burbuja inmobiliaria (a mitades de 2007), producto posiblemente del aumento del coste de acceso a la vivienda.

FIGURA 3 Evolución de las migraciones internas en números absolutos y tasa bruta de migración, CAM у RMB, 1988-2010
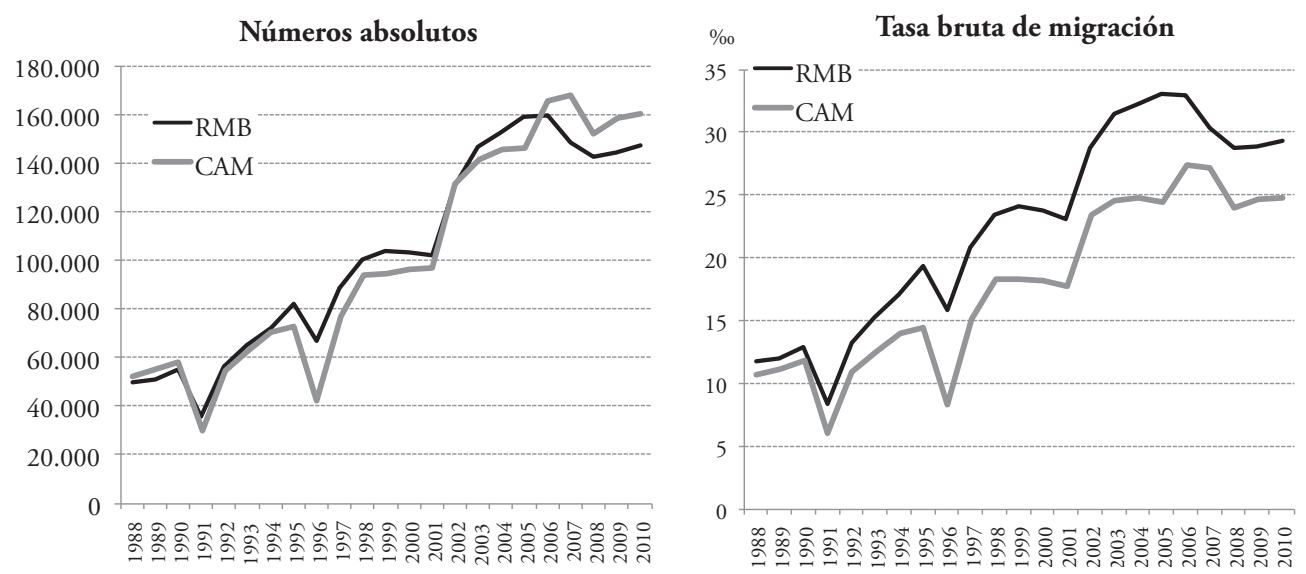

FUENTE EVR (I988-20IO) y PADRÓN CONTINUO (INE), 2OII; Y ESTIMACIONES INTERCENSALES DE POBLACIÓN (INE E IDESCAT)

2 El descenso de los años 1991 y 1996 se debe a la coincidencia con una operación censal (1991) o con la renovación padronal (1996), siendo en estos registros donde se comunicaba el cambio de municipio. 
Las migraciones residenciales metropolitanas.

Un análisis a partir del tamaño de los municipios

Una de las variables explicativas de la movilidad residencial es el tamaño del municipio: a mayor tamaño (y densidad) mayores pérdidas de población. Esto es debido al menor poder de atracción de las ciudades centrales y a la dificultad de establecer allí la vivienda, ya sea por los precios inmobiliarios (más elevados), o por la inexistencia de ciertas tipologías de vivienda (en particular la vivienda unifamiliar) o la mayor dificultad de creación de nuevos espacios urbanos. Para observar este fenómeno se representan en la Figura 4 las tasas brutas internas de inmigración, emigración y el saldo resultante.

En cuanto a la inmigración, en general se cumple la regla de que a menor tamaño, mayores tasas experimentadas. Existe alguna ligera excepción: entre 1988 y 1990 esto no se cumple para los municipios de la RMB más pequeños (menos de 2.000 habitantes), tampoco en la CAM hasta el periodo 2001-2005. En cuanto a la evolución temporal, en general las tasas también son crecientes (con alguna leve excepción entre 1991 y 1995), al mismo tiempo que en el último periodo 2006-2009 se registra un descenso de las tasas en los municipios menores de 50.000 habitantes, descenso de mayor intensidad en la RMB.

Existen menores diferencias por tamańo de la población, si se observan las tasas de emigración. En general se encuentran mayores tasas cuando el municipio es más pequeño, pero no se cumple una correlación tan clara respecto de las tasas de inmigración. Madrid y Barcelona, las dos ciudades centrales y de mayor tamaño, presentan siempre las tasas más bajas. Este hecho es significativo, ya que la pérdida de población de las ciudades centrales no se debe a una mayor expulsión de la población (como a veces se insinúa), sino que es producto de la menor capacidad de atracción. En la evolución temporal se observa cómo las intensidades son crecientes y, al contrario que las tasas de inmigración, no se produce el descenso del último cuatrienio en la CAM, mientras que en la RMB este descenso sí se observa, aunque es poco importante y no se produce en todas las categorías (en las ciudades mayores, o bien, se encuentra estancada, como en Barcelona, o bien, sigue aumentando).

Del cómputo del saldo migratorio interno aparece una situación similar entre ambas metrópolis, con algunos ligeros matices: el centro y las ciudades mayores pierden población, mientras se incrementan los residentes de los municipios más pequeños. Las intensidades son, a grandes rasgos, similares entre Madrid y Barcelona, aunque en la RMB encontramos las tres categorías de municipios mayores incorporados a la dinámica negativa, mientras en la CAM vemos tan solo dos de ellas. En la Rмв la desconcentración residencial alcanzaría, por lo tanto, un número mayor de ciudades, y se observa de forma clara desde finales de los ochenta. En la CAM este proceso se produjo con posterioridad, y se difundió a inicios del siglo Xxi. 
FIgURA 4 | Tasas de inmigración, emigración y saldo neto interno según el tamaño del municipio, САм у Rмв, 1988-2009

\section{INMIGRACIÓN}
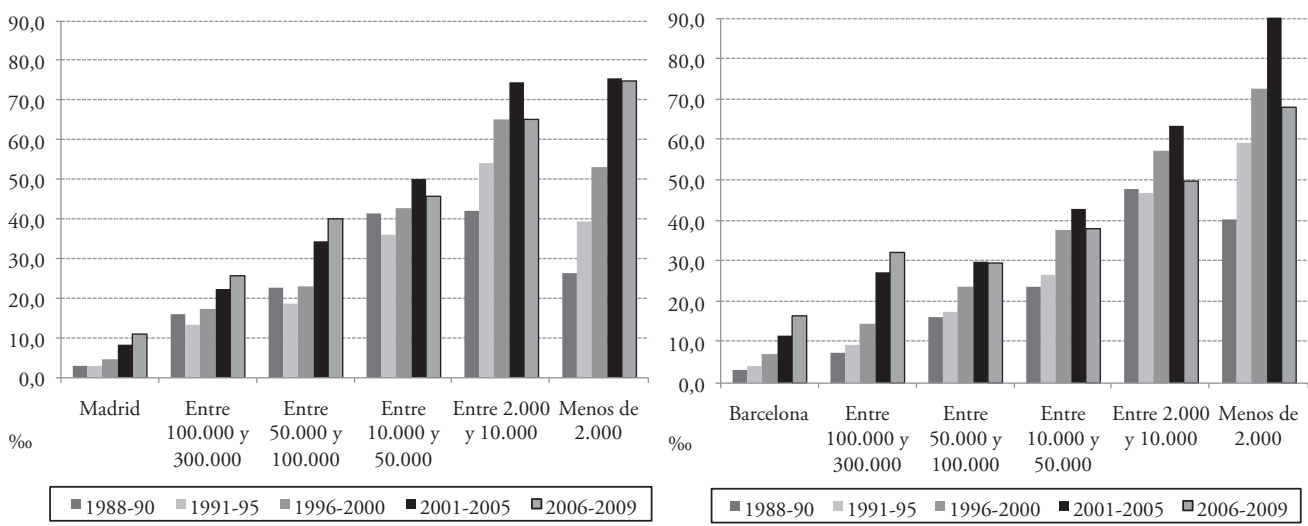

EMIGRACIÓN
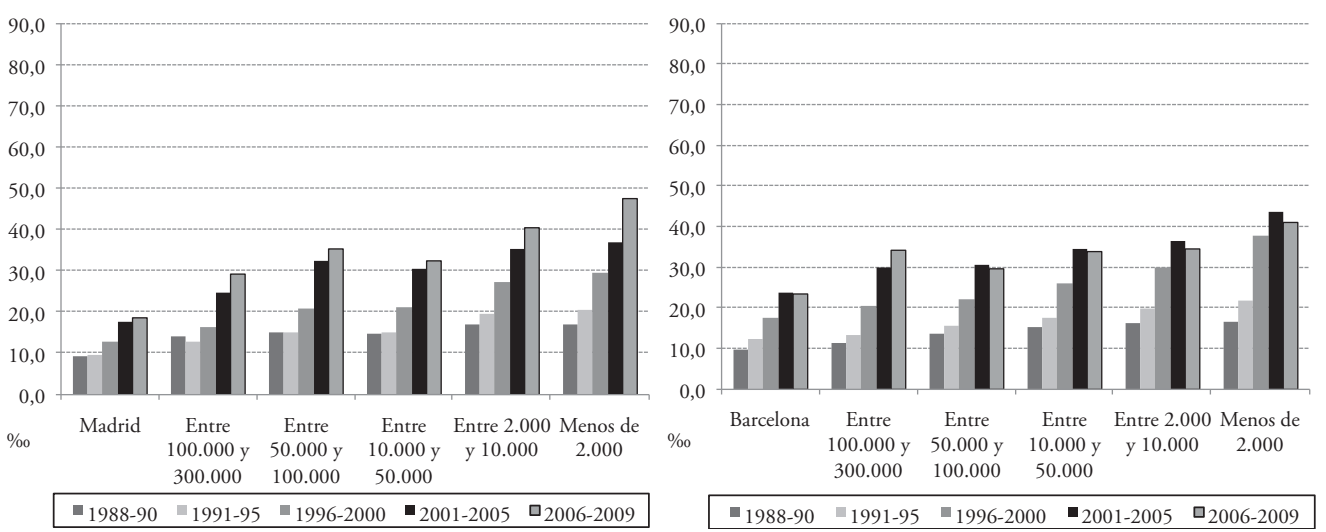

SALDO NETO
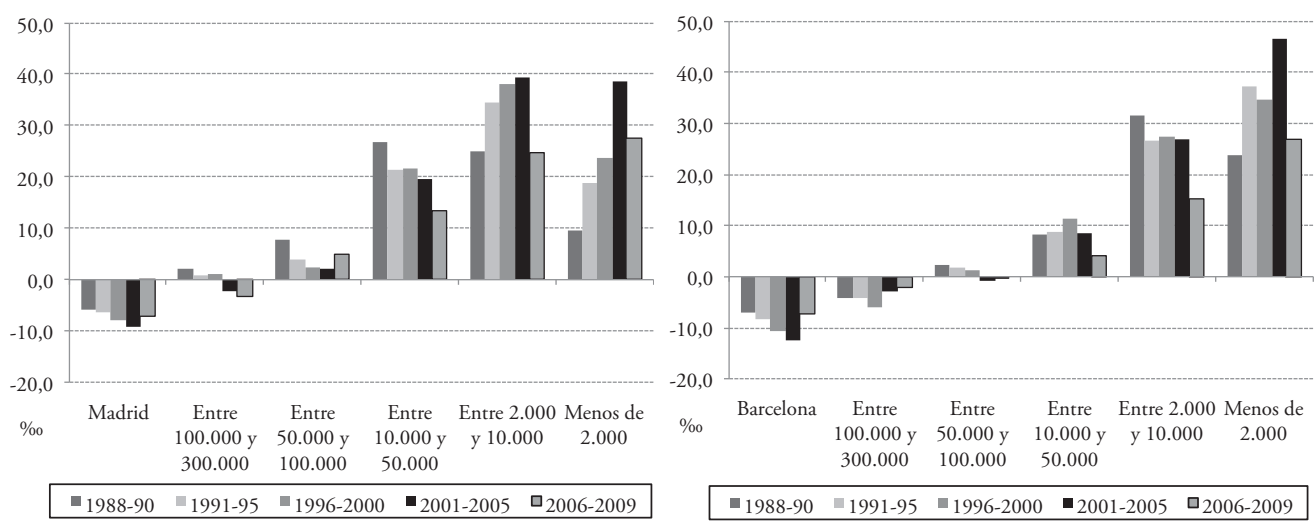

FUENTE EVR (1988-2009) Y PADRÓN CONTINUO (INE) 
El último periodo analizado, 2006-2009, presenta algunas particularidades que rompen con la evolución anterior. Por un lado, por primera vez desde 1988 decrece el saldo migratorio negativo de las ciudades centrales (hecho que, para algunos autores, como López-Gay [2011], puede indicar un inicio del proceso de recentralización), situación más evidente en Barcelona, y que sitúa los valores observados cerca de los experimentados durante los primeros años de la década de los noventa.

\section{Las migraciones residenciales en función de la distancia a la ciudad central}

Junto con el tamaño, la segunda variable que determina el sentido e intensidad de los flujos es la distancia del municipio respecto del centro metropolitano. En este caso solo se representa el saldo migratorio interno neto, en distancias de 10 kilómetros calculados considerando los puntos centrales de cada municipio. Debido al mayor tamaño de Madrid $\left(605,8 \mathrm{~km}^{2}\right)$ en comparación con Barcelona $\left(100 \mathrm{~km}^{2}\right)$, y la mayor extensión de la CAM, las categorías que se muestran no son exactamente las mismas ${ }^{3}$.

FIgURA 5 | Tasas de migración neta interna según la distancia al municipio central, САM У RMB, 1988-2009
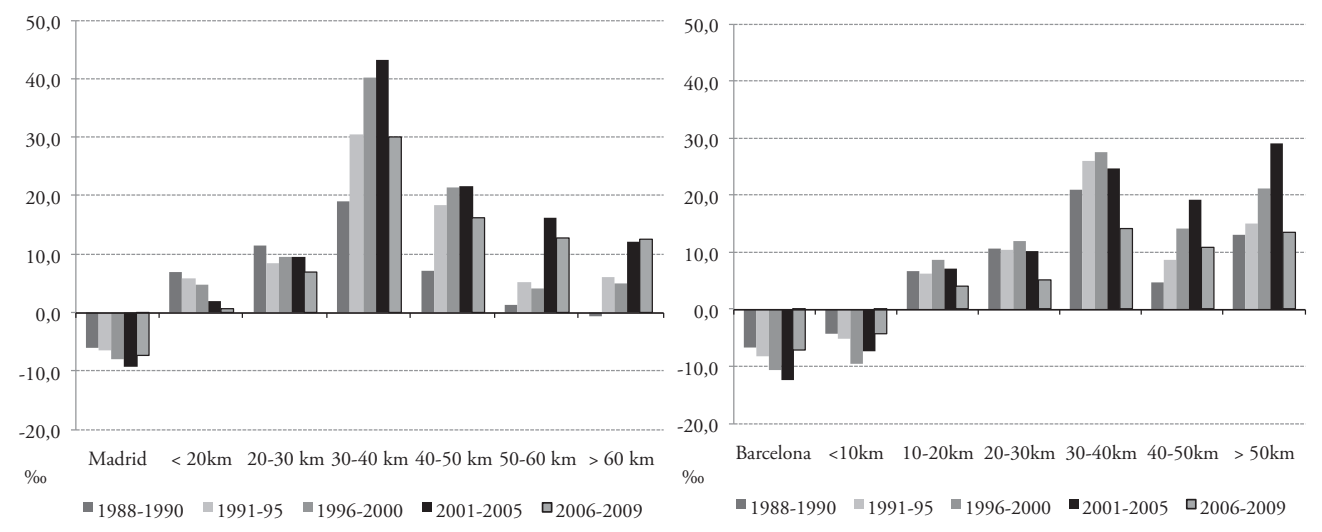

FUENTE EVR (I988-2009) Y PADRÓN CONTINUO (INE)

Los resultados nos indican, en ambos casos, la pérdida de población de la ciudad central, al tiempo que los municipios colindantes experimentan este mismo proceso en la RMB, mientras que el saldo es cada vez menor y prácticamente nulo en la CAM. Los municipios situados entre 30 y $40 \mathrm{~km}$ de la ciudad central son, en ambos casos, los que más crecen. En comparación, en la cam las intensidades del saldo migratorio son mucho mayores, con saldos netos que superan el 40 por mil anual en los primeros años del siglo xxi en algunas categorías. Los municipios más alejados, en cambio, en Madrid no se incorporan plenamente a la dinámica de crecimiento migratorio sino hasta la última década. Finalmente, y de forma similar a los resultados obtenidos por tamaño de población, los cambios observados durante el último

3 En el caso de la CAM no tiene sentido considerar distancias menores a $10 \mathrm{~km}$, ya que incluye un número muy reducido de municipios y población; al contrario, el mayor territorio nos permite sumar una nueva categoría, de más de $60 \mathrm{~km}$. 
periodo son mucho más visibles en la RMB que en la CAM. Los crecimientos observados, de mayor importancia a medida que se incrementa la distancia, se relacionarían con las constantes mejoras en la accesibilidad del territorio que experimentan ambas metrópolis durante las últimas décadas (en el caso de la CAM, además, se verá favorecido por un mejor sistema de transporte público metropolitano).

\section{Las migraciones metropolitanas a escala municipal}

El detalle territorial de las tasas de inmigración y emigración se ha representado en los mapas de las figuras 6 y 7, resumiendo la información en dos periodos: la década de los noventa y los nueve ańos con datos del presente siglo, 2001-2009. Las tasas de inmigración (Figura 6) presentan valores muy elevados y con gran variabilidad territorial; en cambio, las tasas de emigración (Figura 7) se mueven en valores más reducidos y con menores diferencias en el territorio. Si los municipios tienen diferente capacidad de atracción, los niveles de salida o "expulsión", en cambio, no muestran grandes divergencias geográficas. En todos los casos se observa un crecimiento de la movilidad entre ambas décadas, con tasas superiores en el segundo periodo que, además, cubren un mayor campo geográfico, lo que indica una dispersión de la movilidad en el territorio.

En la CAM, el municipio central es el que experimenta la tasa de inmigración más baja en los años noventa, con un valor sólo del 4,1 por mil. Esta situación también se produce en las partes más alejadas del centro de la comunidad, en especial en la zona sur. En la última década, se observa un crecimiento generalizado de las tasas (Madrid cuadriplica el valor, pasando a 16,1 por mil), con tasas más elevadas que las observadas en la RMB. De esta forma, hasta 132 municipios superan valores del 50 por mil, 69 de ellos por encima del 75 por mil. En municipios como Arroyomolinos, Paracuellos del Jarama o Pedrezuela, las tasas incluso superan el 140 por mil anual. En cambio, los municipios más cercanos a la capital y la periferia sur son las zonas donde se observan los valores más reducidos y, por tanto, con menor capacidad de atracción.

En la RMB, las tasas de inmigración guardan una relación estrecha con el tamaño del municipio, con mínimos en Barcelona y las ciudades mayores. En los noventa, Barcelona presentaba una tasa de inmigración metropolitana muy baja (5,7 por mil); Sabadell, Terrassa, Mataró, Santa Coloma de Gramenet o l'Hospitalet de Llobregat, municipios todos ellos de más de 100.000 residentes, se sitúan justo por encima del 10 por mil, intensidades que solo se repiten en algún municipio de la comarca del Penedès (en el oeste de la RMB, y donde la dinámica metropolitana aún no alcanzaba este territorio en los noventa), o en Badia del Vallès (municipio de elevada densidad). Únicamente Sant Cugat del Vallès (43,2 por mil) o Mollet del Vallès (33,3 por mil) muestran gran capacidad de atracción. En contraposición, algunos de los municipios periféricos como Vacarisses u Olivella, por citar algún ejemplo, mostraban valores en torno al 150 por mil, relacionados con un hábitat disperso y con la transformación de segundas residencias en viviendas principales. En la última década, y en comparación con la anterior, se observa un crecimiento generalizado de las tasas en todo el territorio metropolitano. El mínimo barcelonés asciende al 13,6 por mil, y los mínimos acostumbran a superar ahora valores del 25 por mil. Algunos de los municipios con 
tasas más bajas, como L’Hospitalet o Santa Coloma, triplican la tasa de inmigración en relación con la década precedente (situándose en torno al 35 por mil), producto de la movilidad residencial de la población extranjera, creciente en los años más recientes. Los valores superiores al 50 por mil afectan la mayor parte del territorio metropolitano (94 municipios), y en 33 de ellos se supera el 75 por mil.

\section{Figura 6 | Tasas de inmigración interna a escala municipal en la RMB y la CAM según periodos}

$1991-2000$

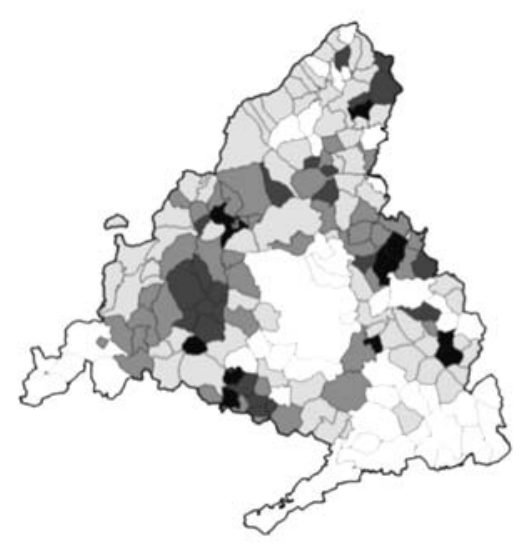

$1991-2000$

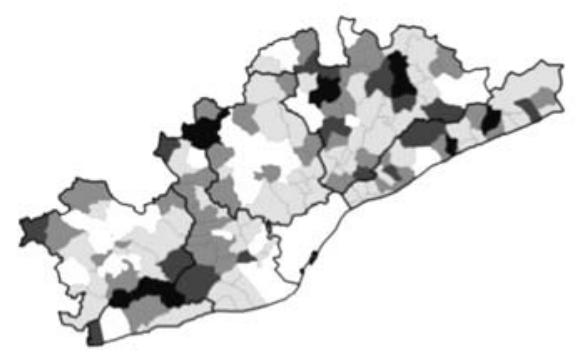

2001-2009

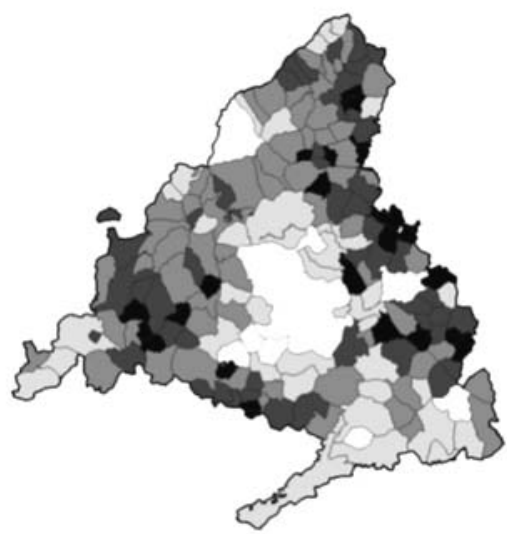

2001-2009

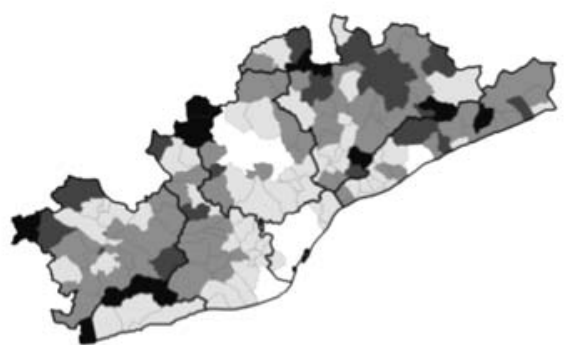

Tasa anual por mil habitantes

Menos del 25 por mil

Del 50,01 al 75 por mil

Más del 100 por mil

Del 25,01 al 50 por mil

Del 75,01 al 100 por mil

FUENTE EVR (I988-2009) Y PADRÓN CONTINUO (INE)

Las tasas de emigración son, en general, menos intensas, aunque también experimentan un crecimiento notable entre los dos periodos (Figura 7). En la RMB ya no es Barcelona el municipio con valores menores; esto se produce en ciudades como Terrassa (8,8 por mil) y Mataró (10,3 por mil), las cuales mantuvieron una alta actividad constructiva en el interior del propio municipio (y, por tanto, con mayor posibilidad de retener población), a diferencia de Barcelona (15,2 por mil). Entre las grandes ciudades, 
Santa Coloma de Gramenet (24,2 por mil) y l'Hospitalet de Llobregat (23,5 por mil) presentan los valores más elevados, que en tan solo un municipio metropolitano, de pequeńas dimensiones, superan el 50 por mil. En la década más reciente se produce un crecimiento generalizado de las tasas, entre el mínimo de Terrassa (15,3 por mil) y máximos que superan el 70 por mil en pequeños municipios periféricos con altas tasas también de inmigración. En la CAM se observa igualmente este incremento generalizado, que aquí sí se produce con notables divergencias territoriales. El norte y este de la CAM muestran las mayores tasas emigratorias, al mismo tiempo que el sur de la comunidad experimenta las tasas más bajas. Madrid varía muy poco entre los dos periodos (de 11,4 a 16,1 por mil), presentando así una de las intensidades más bajas. El mínimo se produce en Aranjuez ${ }^{4}$ (5,1 y 12,1 por mil en los periodos considerados, respectivamente) y los máximos en los municipios del norte de la comunidad.

\section{FIGURA 7 Tasas de emigración interna a escala municipal en la RMB y la CAM según periodos}
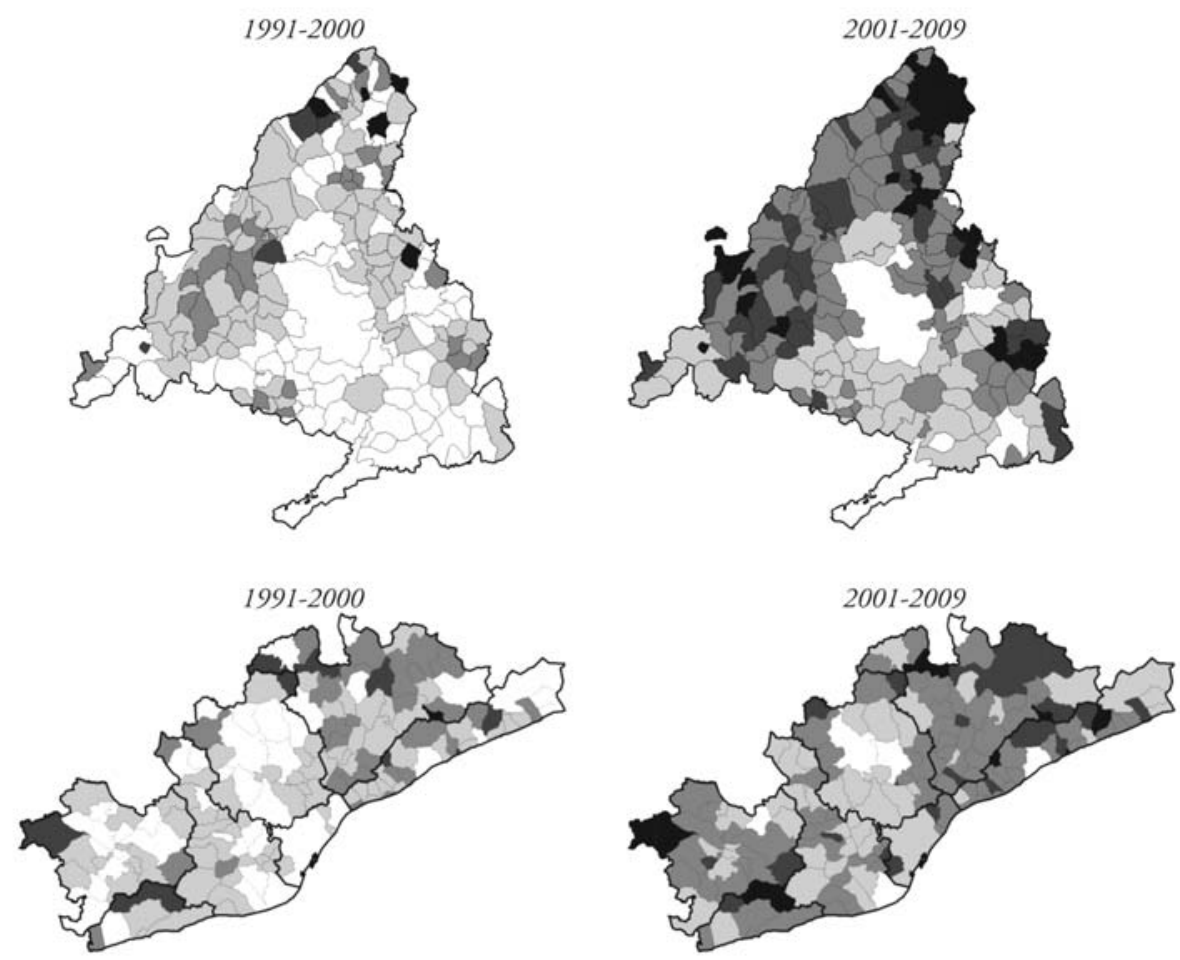

Tasa anual por mil habitantes

Menos del 20 por mil

Del 30,01 al 40 por mil

Más del 50 por mil

Del 20,01 al 30 por mil

Del 40,01 al 50 por mil

FUENTE EVR (I988-2009) Y PADRÓN CONTINUO (INE)

Debido a su carácter periférico, buena parte de sus relaciones migratorias se producen con la provincia de Toledo, lo que explica las bajas tasas de emigración interna a la CAM registradas. 


\section{La estructura por edades de la movilidad}

Los perfiles por sexo y edad de la movilidad residencial son muy parecidos entre las dos regiones metropolitanas, aunque en la RMB adquieren siempre una mayor intensidad (Figura 8). La mayoría de los flujos se concentra entre los 25 y 34 ańos y se relaciona, en buena parte, con la formación de un nuevo hogar (que en España se produce a edades tardías). Son tasas con máximos que ocurren ligeramente más temprano entre las mujeres, debido a las diferencias de edades entre cónyuges. Existe también una migración de arrastre importante en el grupo 0-4 años y un ligero repunte en las edades mayores, coincidiendo con la pérdida de independencia.

FIGURA 8 | Tasas de migración interna por sexo y edad, CAM у RMB, 1991-2000 y 2001-2009
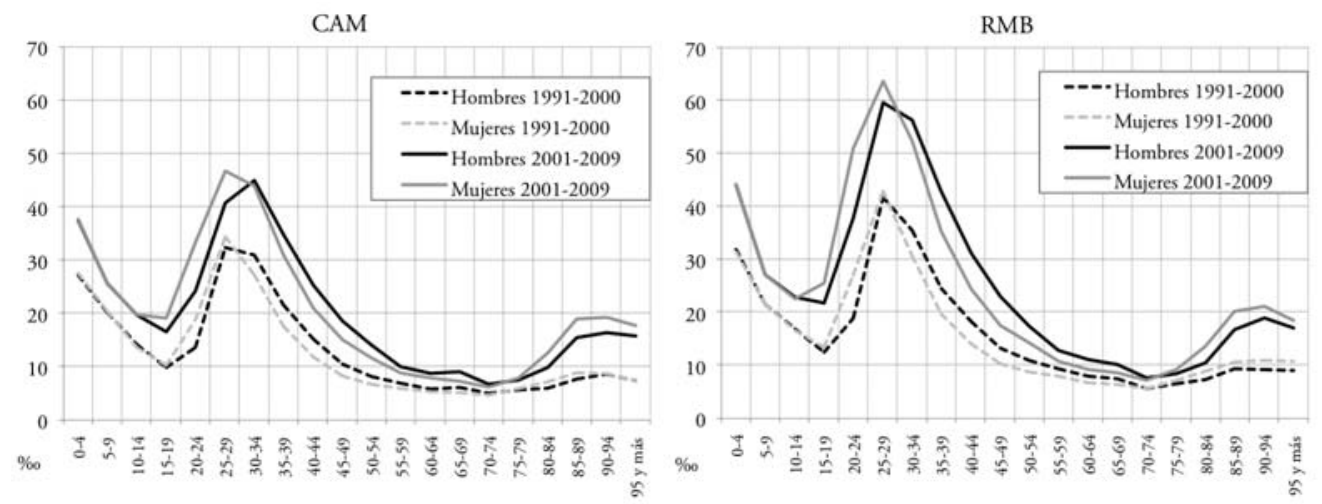

FUENTE EVR (I99I-2009) Y PADRÓN CONTINUO (INE, IDESCAT E INSTITUTO DE ESTADÍsTICA DE MADRID)

Entre la década de los noventa y la primera del siglo xxi se observa un crecimiento general de las tasas, que incluso se doblan en las edades por encima de los 85 años. Esta última situación, que se observa tanto en la CAM como en la RMB, significa un cambio substancial en relación con las pautas de movilidad preexistentes. El cambio de residencia a estas edades debe ser relacionado con movimientos residenciales previos de los hijos, ya sea por una movilidad con destinación a un hogar de descendientes (localizados en la periferia), ya sea en una institución cercana a la vivienda de los hijos. Por otro lado, también las diferencias entre hombres y mujeres son un poco más acusadas en los grupos de mayor movilidad en los últimos ańos, aunque la existencia de una alta proporción de extranjeros en las edades de mayor movilidad pueda explicar esta tendencia. La tercera característica, que se repite en ambos periodos, es la menor movilidad en la CAM, aunque los perfiles por sexo y edad sean muy similares. El tamaño de la ciudad central influye en las diferencias entre las tasas de ambas metrópolis, no tanto por una razón de superficie (Madrid sextuplica a Barcelona), ya que las tasas de Madrid son muy similares a las de Barcelona, sino porque la primera todavía tiene un peso más importante en relación con la CAM que Barcelona con la RMB. Además, cabe señalar que en 
el caso de Madrid aún ha sido posible la construcción de extensas promociones residenciales dentro de los límites de la ciudad central (De la Riva, Palacios \& Vinuesa, 2011), situación que en Barcelona ha sido de menor magnitud.

\section{El caso específico de las ciudades centrales}

Por el peso que representan sobre el conjunto de los flujos y el impacto sobre el resto del territorio, es importante presentar qué sucede en las ciudades centrales, caracterizadas por la continuidad de unos saldos migratorios internos negativos. El perfil de los inmigrantes, emigrantes y el saldo resultante se presenta en la Figura 9, donde se observa la pérdida de jóvenes con destino a las periferias metropolitanas.

\section{FIGURA 9 | Tasas de inmigración, emigración y migración neta para las ciudades} de Madrid y Barcelona, 2001-2009
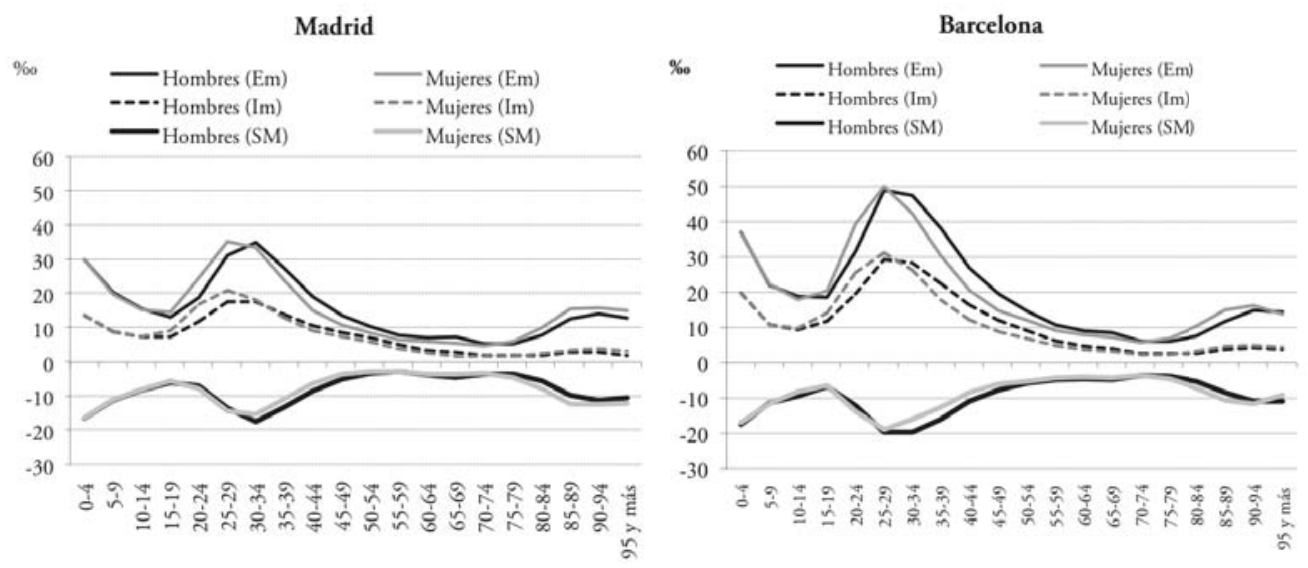

FUENTE EVR, 200I-2009 (INE), Y PADRÓN CONTINUO (IDESCAT E INSTITUTO DE ESTADístiCA DE LA COMUNIDAD DE MADRID)

Aunque existen notables diferencias en la intensidad de las entradas y salidas de la ciudad central (mayores en Barcelona en comparación con Madrid), las tasas de migración neta son prácticamente idénticas. La única excepción recae en las edades más jóvenes: entre los 20 y 29 años de edad, en Barcelona la migración neta (siempre negativa) es más intensa; en contraposición, por encima de los 80 años es en Madrid donde los saldos netos son ligeramente mayores. La pérdida de jóvenes es además selectiva, desde un punto de vista sociodemográfico, con un impacto sobre los niveles de fecundidad mucho más reducidos en los centros metropolitanos que en sus periferias (Pujadas \& López-Villanueva, 2005). En estas, la repercusión de la llegada de los migrantes metropolitanos es mayor, debido a una estructura por edades joven y el mayor nivel de fecundidad. Para López-Gay (2008), las grandes ciudades, como es el caso de Barcelona, generan un filtro sociodemográfico que selecciona quien entra, sale o se mueve dentro de los límites de la propia ciudad. Esta selección expulsa a los más jóvenes, pero también dificulta la entrada de aquellos con menor nivel de estudios e ingresos. 


\section{La creciente participación de los extranjeros en la movilidad residencial metropolitana}

El fuerte crecimiento de las migraciones internacionales en España (de un 2 por ciento de población extranjera a más del 12 por ciento en una década) ha repercutido en todos los fenómenos demográficos (Gozálvez, 2010). Claro ejemplo de ello es la participación de los extranjeros en las migraciones internas, que ha experimentado un fuerte crecimiento desde inicios del siglo xxi (Recańo, 2002; Domingo \& Recaño, 2008; Bayona, Gil-Alonso \& Pujadas, 2011; Bayona \& Gil-Alonso, 2012; Pumares, García-Coll \& Asensio, 2006). Extranjeros han protagonizado tres de cada diez migraciones internas en 2008 , un 27,7 por ciento si estas son intraprovinciales, o el 33,7 por ciento si son entre diferentes provincias. Evidentemente, en el caso que nos atañe, los valores alcanzados son superiores: un 37,3 por ciento de las migraciones internas en la CAM en 2009, y un 41,3 por ciento en la RMB en 2008, son protagonizadas por extranjeros (Figura 10), con una dinámica creciente que modifica la pauta general, tanto en su intensidad como en la localización territorial. Los flujos residenciales de españoles habrían alcanzado sus máximos con anterioridad, manteniéndose en cifras bastante similares durante la última década en la CAM, o incluso con un descenso acusado en la RMB (del 26 por ciento entre 2003 y 2008), situación que facilitaría la mayor representación de los extranjeros en la RMB.

FIGURA 10 | Evolución de las migraciones internas de extranjeros, CAM у RMB, 1988-2009

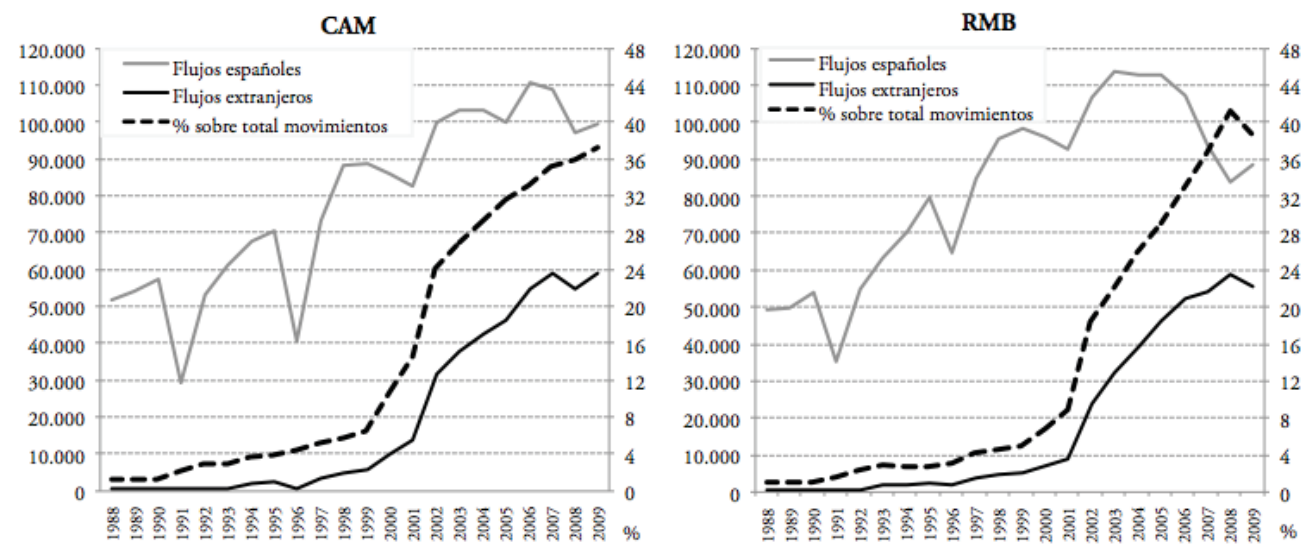

FUENTE EVR, I988-2009 (INE)

La intensidad de la movilidad de los extranjeros es mucho más elevada que la de los españoles, como se desprende directamente de su participación en los flujos, muy por encima de su peso sobre el conjunto de la población $(17,5$ por ciento en Madrid y Barcelona, por 16,7 por ciento en la CAM y 14,8 por ciento en la Rмв). Esto se debe a una movilidad que se extiende a lo largo de todas las edades activas, y no solo en los años de emancipación familiar o en los primeros pasos de 
una familia. La reciente llegada de muchos de ellos, coincidiendo con los años del boom migratorio internacional, y la provisionalidad relacionada con estas primeras etapas de asentamiento, tanto residencial como laboral, explican las mayores tasas observadas.

FIgURA 11 | Proporción de extranjeros en la movilidad residencial según municipio, CAM y RMB, 2001-2009

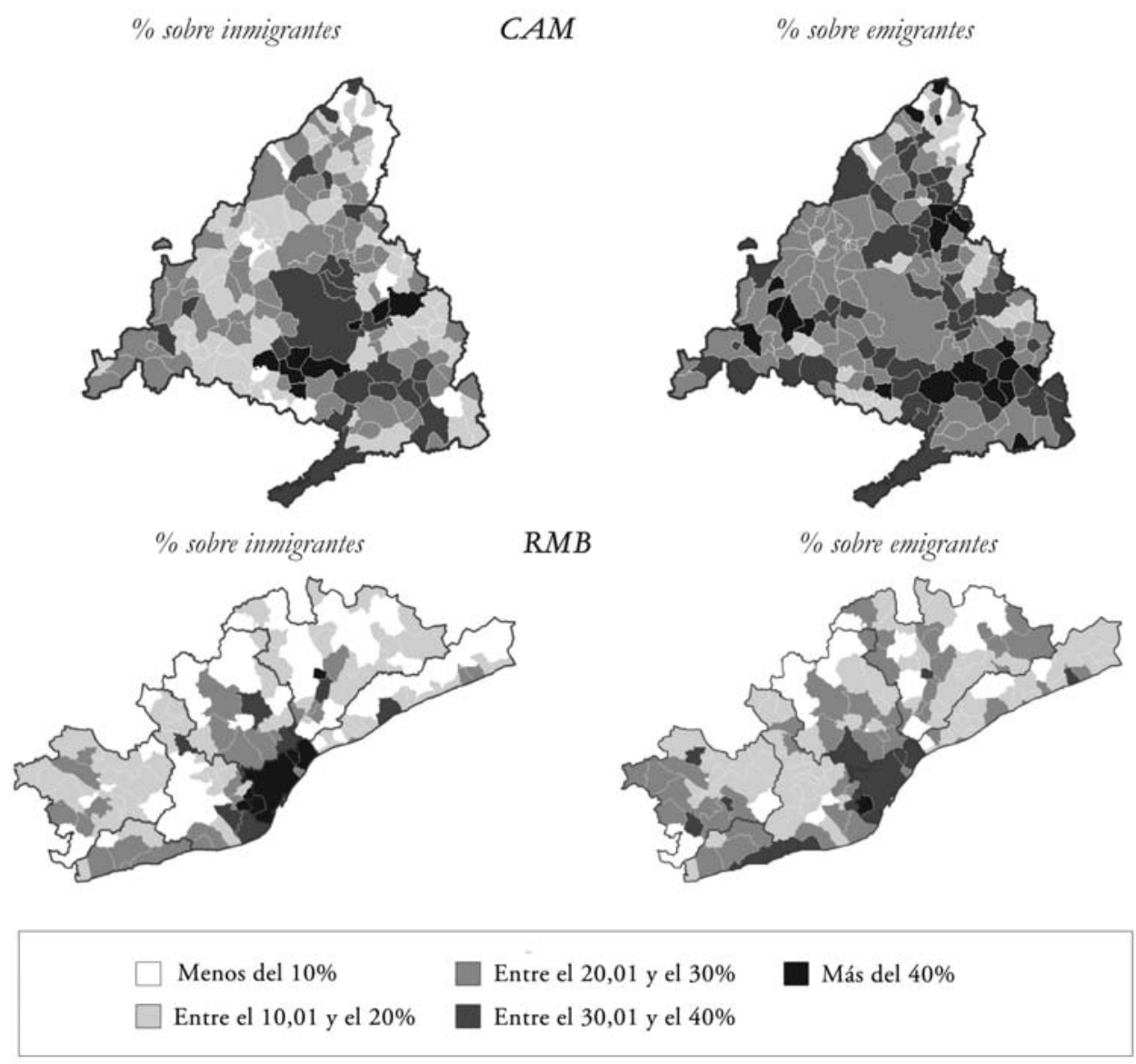

FUENTE EVR, 2OOI-2009 (INE)

Geográficamente, su incidencia sobre el conjunto de la movilidad es muy dispar. En la Figura 11 se representa el peso de los extranjeros en las entradas y salidas por municipio para la última década, periodo en que mayor ha sido dicha movilidad. En el caso de la RMB, en algunos municipios más de la mitad de toda la movilidad es protagonizada por extranjeros (Bayona \& López-Gay, 2011). Ejemplo de ellos son Santa Coloma de Gramenet o L'Hospitalet, donde respectivamente el 61,7 y el 58,2 por ciento de las entradas desde otro punto de la RMB la producían extranjeros, o el 39,9 o 41,3 por ciento de las salidas respectivas. En Barcelona estas cifras también son muy importantes, del 40,9 y 36,2 por ciento, respectivamente. En cambio, en 
los municipios con mayores tasas de inmigración, donde se localizan los migrantes residenciales de nacionalidad española preferentemente, la participación de los extranjeros es baja. La movilidad metropolitana, como mínimo en los municipios centrales y en los de mayor tamańo, debe ser comprendida considerando la alta participación de extranjeros. En este caso, el continuum urbano de la ciudad central es el que experimenta los intercambios más elevados de extranjeros, ya sea por tratarse de un mismo mercado inmobiliario, ya sea porque los españoles se dirigen menos hacia estos municipios.

En la CAM se observan pautas similares, aunque los valores alcanzados no sean tan extremos: en Parla, los extranjeros representan el 49,4 por ciento de las entradas y el 48,9 por ciento de las salidas; en Madrid, estos valores son del 37,4 y 29,7 por ciento, inferiores a los experimentados por Barcelona. La diferencia reside en que en la CAM este fenómeno se distribuye por territorios más amplios, mientras que en Barcelona se localiza en las áreas centrales. En la CAM, en la mayoría de municipios los extranjeros representan más del 10 por ciento de los inmigrantes, pero, al mismo tiempo, dan cuenta de más del 20 por ciento de los emigrantes. Las migraciones de extranjeros muestran una pauta territorial caracterizada por la desconcentración de la ciudad central, aunque se dirigen a municipios con diferentes características de los que reciben población española (dominando aquellos más cercanos y densos).

\section{La estructura territorial de la movilidad: la existencia de subcentros que articulan el territorio}

Barcelona y Madrid articulan las migraciones metropolitanas, siendo el origen principal de la mayoría de flujos recibidos por los distintos municipios metropolitanos. A pesar de esta preeminencia, en algunos casos existen subcentros metropolitanos con un elevado peso en la movilidad interna de sus alrededores, o que están en un segundo lugar después de la relación con la capital. Para establecer estos espacios migratorios, se ha representado el primer y segundo origen de los flujos migratorios internos recibidos por cada municipio (Figura 12), considerando el periodo más reciente (2001-2009).

Los resultados obtenidos para la CAM inciden en el fuerte papel que desempeña la ciudad central en la articulación del territorio. De los 179 municipios, 155 tienen en Madrid el principal origen de los flujos migratorios internos, y en los 24 restantes Madrid aparece en segunda posición. Únicamente las ciudades de Fuenlabrada y Alcalá de Henares muestran un ámbito propio de dispersión de cierta entidad como primer origen. Si se considera, en cambio, el segundo municipio, aparece una fuerte complejidad territorial. Por un lado, entre los municipios de la sierra norte, Buitrago de Lozoya ejerce de clara cabecera comarcal. Además, Móstoles, Arganda del Rey, Alcobendas, Torrejón de Ardoz o Collado Villalba muestran un ámbito próximo de influencia muy destacado. Al mismo tiempo, un buen número de municipios tiene dinámicas propias emergentes y menos estructuradas.

En el caso de la RMB, dos tercios de los municipios (106) tienen su principal origen migratorio en Barcelona, aunque siete ciudades intermedias desempeñan un papel importante en la articulación de los municipios próximos. Es el caso de Vilafranca del Penedès, 
Sabadell, Terrassa, Granollers, Badalona, Mataró y Vilanova i la Geltrú. Si se considera un segundo origen, además de la consolidación de los espacios relacionales de estas mismas ciudades, aparecen también los casos de L'Hospitalet de Llobregat y Mollet del Vallès, y se consolida el papel de Badalona. El primero articula buena parte del oeste metropolitano, en especial toda la cuenca del Llobregat, mientras que Badalona hace lo mismo en dirección a la comarca del Maresme. Treinta y nueve municipios tienen su segundo origen en Barcelona. A pesar del peso de Barcelona, alrededor de unos veinte municipios no tienen a la ciudad entre sus dos principales municipios emisores de inmigrantes.

FIGURA 12 Primer y segundo origen de las migraciones metropolitanas, CAM y Rмв, 2001-2009

Primer origen

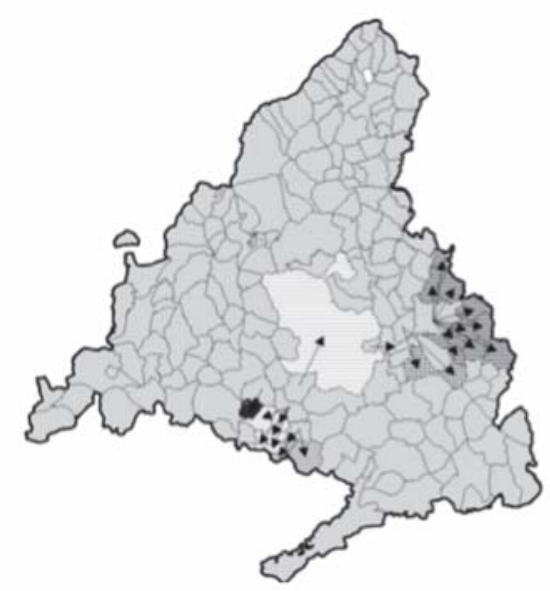

$C A M$

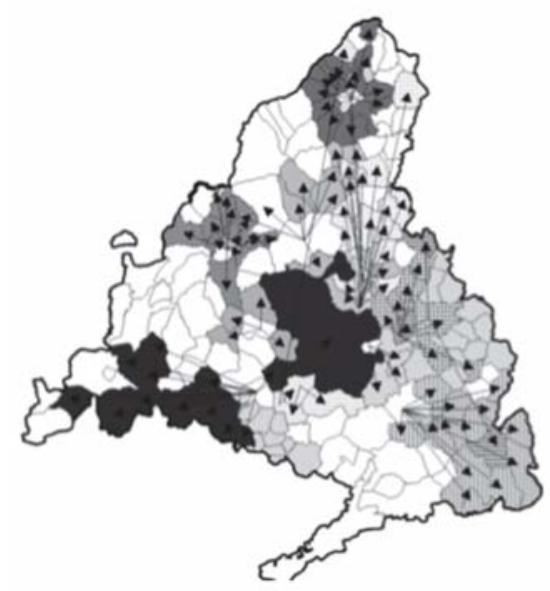

Madrid 曲 Torrejón de Ardoz $\square$ Fuenlabrada

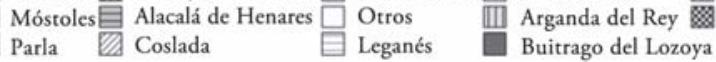

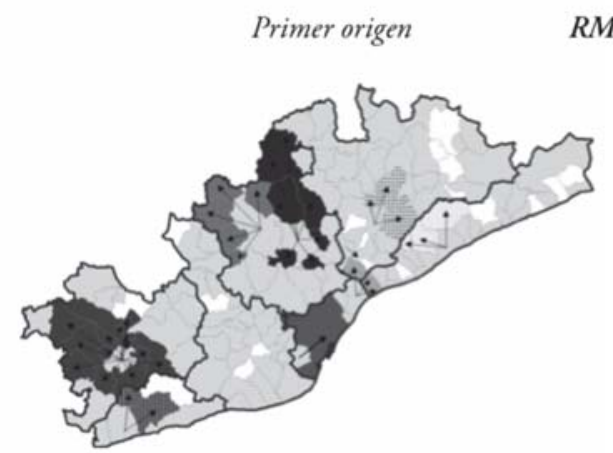

$R M B$

Segundo origen

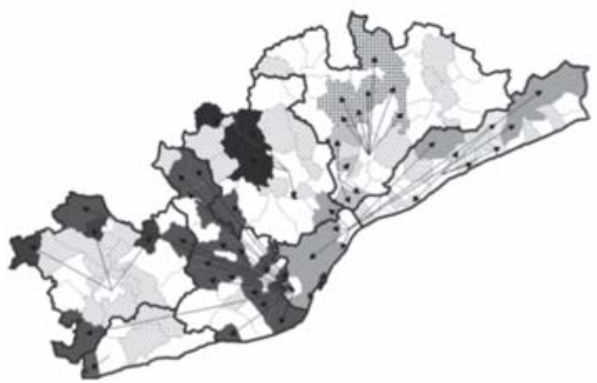

Barcelona
Badalona
Granollers
L'Hospitalet de Llobregat
Mataró
Mollet

Sabadell

Otros Municipios

Terrassa

Vilafranca del Panadés

Vilanova i la Geltrú

FUENTE EVR, 200I-2009 (INE) 
Finalmente, se ha empleado el coeficiente de interacción, que relaciona tanto los flujos de entrada como de salida, teniendo en cuenta el conjunto de la movilidad metropolitana (Figura 13). De esta forma se calcula un valor de interacción entre todos los municipios y para cada uno de ellos, representándose únicamente los valores más intensos. En este caso, el resultado reafirma los espacios migratorios detectados con anterioridad. Tanto Madrid como Barcelona, por ser las ciudades centrales y mayores, mantienen extensas relaciones con la mayoría de los municipios metropolitanos. Madrid desarrolla una alta interacción con todos los municipios más importantes de la comunidad. A un segundo nivel, Alcalá de Henares (este), Parla y Móstoles (sur) y Majadahonda (norte) articulan flujos importantes con los municipios vecinos. En la RMB, las relaciones de Barcelona con las ciudades mayores de la segunda corona metropolitana son de menor entidad, al tiempo que estas articulan con mayor claridad que en la CAM sus espacios circundantes. Las barreras físicas (pequeñas serranías y valles fluviales) son únicamente superadas en relación con la ciudad central, y se mantiene una fuerte articulación comarcal del territorio.

\section{FIgURA 13 | Espacios de interrelación migratoria a partir del coeficiente de interacción, 2001-2009, САM У RMB}

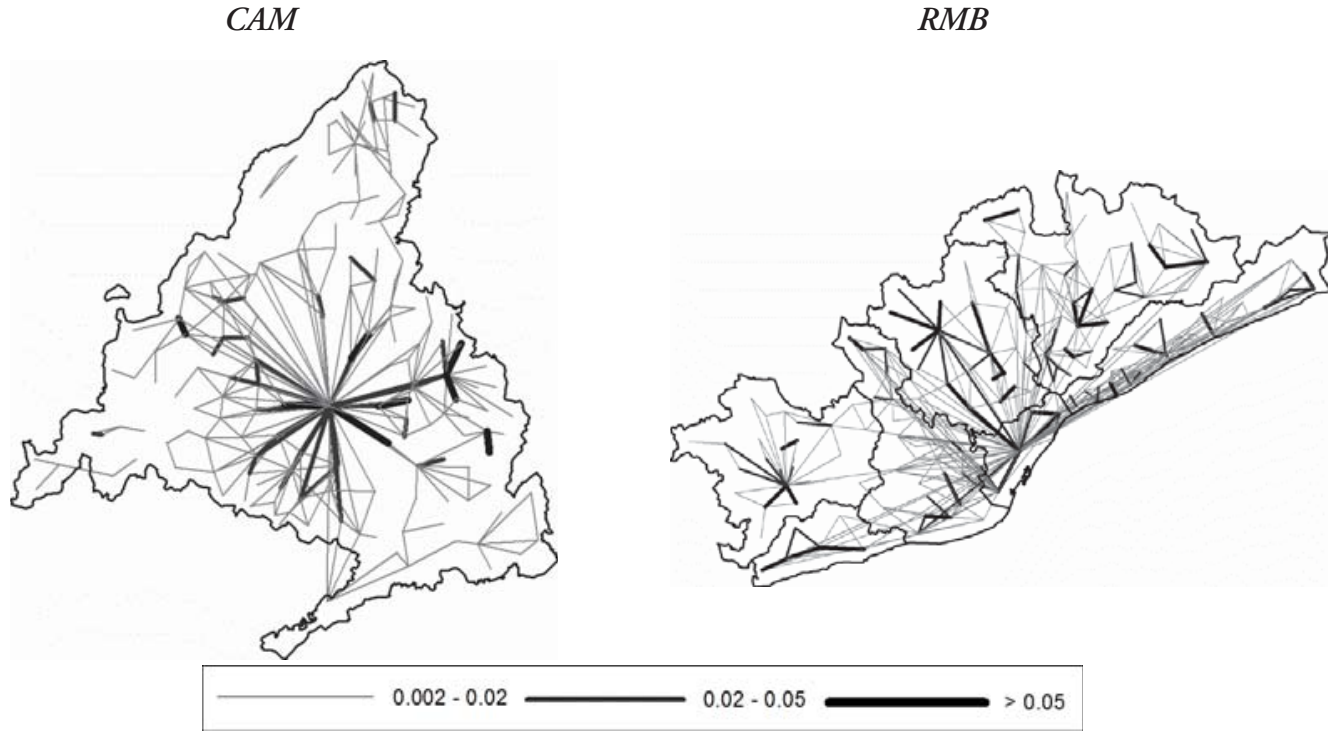

FUENTE EVR, 200I-2009 (INE)

\section{Conclusiones}

La intensidad de la movilidad residencial en las dos regiones metropolitanas ha sido creciente durante las últimas décadas, aunque en la actualidad nos encontramos en un punto de inflexión e incertidumbre a consecuencia de la crisis económica. En la comparación entre las dos mayores regiones metropolitanas espańolas, encontramos múltiples semejanzas en la evolución y en las características de los flujos, aunque en 
la RMB el proceso adquiere mayor madurez, ya que anticipa algunos de los comportamientos que más tarde se observan también en la CAM. El incremento de la movilidad residencial de los últimos años se relaciona directamente con la pérdida de peso de las ciudades centrales y el crecimiento demográfico de las periferias, siendo la movilidad una de las principales causantes de la dispersión residencial. Como resultado, las metrópolis actuales adquieren mayor grado de complejidad por una mayor dispersión de su población.

Se observa que, en ambos casos, las migraciones residenciales de españoles ya se venían frenando desde unos años atrás. Los máximos de 2006 (RMB) y 2007 (CAM) para el conjunto de movimientos serían anteriores (2003 y 2006 respectivamente), si nos fijamos tan solo en la evolución de la movilidad de los espańoles; el mencionado descenso, por lo tanto, se produciría con antelación a la crisis inmobiliaria, y respondería al aumento general del coste de acceso a la vivienda en propiedad.

En cuanto al sentido de los flujos, se constata que existen menores diferencias en la expulsión que en la atracción de migrantes. Las tasas de emigración son muy parecidas en todo el territorio (e incluso menores en las ciudades más grandes); en cambio, las diferencias en la atracción de migrantes es acusada y territorialmente significativa. Las ciudades centrales pierden población no por una mayor expulsión (que de hecho es menor que en otros ámbitos, al contrario de lo que se cree de forma extendida), sino por su menor poder de atracción. En cambio, los saldos netos por distancia indican que la población se desplaza cada vez más lejos, situación que incluso -según varios autores- empieza a superar el propio marco territorial de análisis aquí utilizado. De esta forma, la población necesita de mayores distancias para conseguir sus preferencias residenciales, con el consiguiente aumento de la distancia y del tiempo empleado diariamente en lo que se conoce como movilidad cotidiana.

Un factor capital en la evolución reciente de la movilidad es la presencia de inmigrantes extranjeros en los flujos. La redistribución de esta población a nivel metropolitano se produce con fuerte intensidad, y ha provocado en pocos años variaciones muy importantes en la composición de la población de algunos municipios. Madrid y Barcelona han actuado como puerta de entrada para los migrantes internacionales, que progresivamente se asientan en el resto del territorio metropolitano. Si esta mayor movilidad se relaciona con su reciente llegada y se produce en todas las edades económicamente activas, la ralentización del fenómeno migratorio debido a la crisis, así como un mayor tiempo de permanencia en España, pueden hacer variar muy rápidamente las pautas observadas en la actualidad. En esta ocasión, el tamaño diferencial de las ciudades centrales significa una mayor movilidad residencial entre municipios en la RMB, ya que algunos desplazamientos que en la CAM se producen dentro de la misma capital aparecen como cambios de municipio.

En cuanto a la estructura territorial de los flujos, además del diferente peso y tamańo de la ciudad central, la estructura más policéntrica de la RMB, basada en una red urbana más consolidada y en la existencia de subcentros de mayor tamańo, ofrece una articulación de los flujos migratorios que difiere de la CAM, donde la ciudad central aún organiza buena parte del territorio metropolitano, a pesar de la incipiente aparición de nuevos subcentros metropolitanos. La estructura espacial de la movilidad en la RMB se encontrará mejor definida que en la CAM. 
Finalmente, cabe considerar las consecuencias de esta elevada movilidad residencial y, con ello, de la redistribución de la población en el territorio. El crecimiento acelerado de algunas áreas periféricas (con perfiles por edades muy jóvenes) crea una mayor diferenciación del territorio y una especialización de zonas residenciales, debido al tipo de vivienda en muchos casos buscada (y ofertada). Si bien es cierto que el proceso de suburbanización de la población se produce al mismo tiempo que las ciudades centrales desconcentran su mercado laboral, la redistribución de la población significa un aumento de la movilidad habitual, por motivo de trabajo y estudio, con unos territorios cada vez más complejos y difíciles de gestionar y planificar. Existe, además, una creciente segregación demográfica: los centros envejecen al mismo tiempo que contienen familias con menos hijos, experimentado por menor fecundidad, mientras que, en las periferias, al impacto del crecimiento demográfico se le debe sumar el de una población joven y con mayor fecundidad, situación que provoca una presión aún mayor sobre los servicios y equipamientos necesarios para hacer frente a una población joven y con una dinámica demográfica creciente. OEURE

\section{Referencias bibliográficas}

Bayona, J. \& Gil-Alonso, F. (2012). Suburbanisation and international immigration: the case of the Barcelona Metropolitan Region (1998-2009). Tijdschrift voor economische en sociale geografie, 103(3), 312-329. doi: 10.1111/j.1467-9663.2011.00687.x

Bayona, J.; Gil-Alonso, F. \& Pujadas, I. (2011). Inmigración extranjera y el proceso de suburbanización en las principales áreas urbanas españolas (1999-2008). En I. Pujadas, J. Bayona, A. García-Coll, F. Gil, C. López, D. Sánchez \& T. Vidal (Eds.), Población y espacios urbanos (pp.801 - 818). Barcelona: Departament de Geografia Humana de la Universitat de Barcelona y Grupo de Población de la Asociación de Geógrafos Españoles (AGE). Disponible en http:// www.ub.edu/congreso_poblacion/docs/actas.pdf

Bayona, J. \& López-Gay, A. (2011). Concentración, segregación y movilidad residencial de los extranjeros en Barcelona. Documents d'Anàlisi Geogràfica, 57(3), 381-412. Disponible en http:// diposit.ub.edu/dspace/bitstream/2445/22643/1/588400.pdf

Bayona, J. \& Pujadas, I. (2010). Cambios residenciales internos en la ciudad de Barcelona: evolución y características territoriales. Investigaciones Geográficas, 52, 9-36. Disponible en http://rua. ua.es/dspace/handle/10045/21201

Bonvalet, C. \& Fribourg, A. M. [Eds.] (1990). Stratégies résidentielles. Vol. 2. París: Institut National d'Études Démographiques (INED), Col. Congrès et Colloques.

Borja, J. (2010). Llums i ombres de l'urbanisme de Barcelona. Barcelona: Empúries.

Cabré, A. \& Módenes, J. A. (1997). Dinàmiques demogràfiques recents a la Regió Metropolitana de Barcelona. Revista Econòmica de Catalunya, 33, 66-76.

Champion, A. G. (2001). Urbanization, suburbanization, counterurbanization and reurbanization. En R. Paddison (Ed.), Handbook of Urban Studies (pp. 143-161). Londres: Sage Publications.

Cheshire, P. (1995). A new phase of urban development in Western Europe? The evidence for the 1980s. Urban Studies, 7(32), 1045-1063. doi: 10.1080/00420989550012564

Clark, W. \& Onaka, J. (1982). Life cycle and housing adjustment as explanations of residential mobility. Urban Studies, 20, 47-57. doi: 10.1080/713703176 
Clark, W. \& Withers, S. D. (2007). Family migration and mobility sequences in the United States: Spatial mobility in the context of the life course. Demographic Research, 17(20), 591-622. doi: http://dx.doi.org/10.4054/DemRes.2007.17.20

Coombes, M., Green, A. E. \& Openshaw, S. (1986). An efficient algorithm to generate official statistical reporting areas: the case of the 1984 travel-to-work areas revision in Britain. Journal of the Operational Research Society, 37, 943-953. doi:10.1057/jors.1986.163

Courgeau, D. (1985). Interaction between spatial mobility, family and career life-cycle: A French survey. European Sociological Review, 1(2), 139-162. URL estable: http://www.jstor.org/stable/522411

De la Riva, J. M.; Palacios, A. \& Vinuesa, J. (2011). Demanda de vivienda, crecimiento residencial y segregación socio-espacial: el caso de los paus madrileños. En V. Gozálvez \& J. A. Marco (Eds.), Urbanismo expansivo: de la utopía a la realidad. Actas del XXII Congreso de Geógrafos españoles (pp. 191-202), Universidad de Alicante.

Domingo, A. \& Recaño, J. (2008). Inmigración internacional y población extranjera: evolución demográfica. En E. Aja, J. Arango \& J. Oliver (Eds.), La inmigración en la encrucijada. Anuario de la inmigración en España, 2008 (pp. 36-60). Barcelona: Centro de Información y Documentación Internacionales en Barcelona (СІDов). Disponible en http://bit.ly/120yX4V

Esteban, J. (2003). La Regió Metropolitana de Barcelona. Revista Papers (Institut d'Estudis Regionals i Metropolitans de Barcelona), 39, 31-41. Disponible en http://www.iermb.uab.es/htm/ revistaPapers_numeros.asp?id=10

Feijten, P. \& van Ham, M. (2007). Residential mobility and migration of the separated. Demographic Research, 17(21), 623-654. doi: 10.4054/DemRes.2007.17.21

García-Coll, A. (2009). Migraciones interiores y transformaciones territoriales. En J. J. Pons, C. Montoro, C. López M. C. \& Barcenilla (Eds.), Territorio y movilidad interior de la población en España (pp. 13-40). Pamplona: Ediciones Universidad de Navarra, S.A.

García-López, M.-A. (2012). Urban spatial structure, suburbanization and transportation in Barcelona. Journal of Urban Economics, 72(2), 176-190.

García-Palomares, J. C. \& Pozo, E. (2010). Movimientos migratorios en la Comunidad de Madrid: unos flujos más intensos y complejos (1991-2006). Boletín de la AGE (Asociación de Geógrafos Espańoles), 53, 89-119. Disponible en http://age.ieg.csic.es/boletin/53/05Garcia por ciento2089-119.pdf

Gozálvez, V. (2010). Los extranjeros residentes en España: su aportación a la demografía. Investigaciones Geográficas, 52, 99-136. Disponible en http://rua.ua.es/dspace/handle/10045/21204

Hall, P. (1971). Spatial structure of the metropolitan England and Wales. En M. Chisholm \& G. Maners (Eds.), Spatial policy problems of the British economy (pp. 96-125). Cambridge: Cambridge Universtity Press.

Kabisch, N. \& Haase, D. (2011). Diversifying European agglomerations: evidence of urban population Trends for the 21st century. Population, Space and Place, 17(3), 236-253. doi: 10.1002/ psp.600

Kritz, M. \& Gurak, D. (2001). The impact of immigration on the internal migration of natives and immigrants. Demography, 38(1), 133-145.

Kulu, H. (2008). Fertility and spatial mobility in the life course: evidence from Austria. Environment and Planning, A, 40(3), 632-652. doi:10.1068/a3914 
Lesthaeghe, R. (1995). The second demographic transition in Western countries: An interpretation. En K. O. Mason \& A. M. Jensen (Eds.), Gender and family change in industrialized countries (pp. 17-62). Nueva York: Oxford University Press.

López-Gay, A. (2008). Canvis residencials i moviments migratoris en la renovació poblacional de Barcelona. Barcelona: Consell de Treball Econòmic i Social de Catalunya (ctesc). Col-lecció Tesis Doctorals. Disponible en http://www.tdx.cat/handle/10803/4971

López-Gay, A. (2011). ¿Vuelve el centro? Caracterización demográfica de los procesos de reurbanización en las metrópolis espańolas. En I. Pujadas, J. Bayona, A. García-Coll, F. Gil, C. López, D. Sánchez \& T. Vidal (Eds.), Población y espacios urbanos (pp. 163-180). Barcelona: Departament de Geografia Humana de la Universitat de Barcelona y Grupo de Población de la Asociación de Geógrafos Españoles (AGE). Disponible en http://www.ub.edu/congreso_ poblacion/docs/actas.pdf

López-Villanueva, C.; Pujadas, I. \& Bayona, J. (2011). Households in the residential mobility process: Family structure and housing characteristics in the metropolitan region of Barcelona. 23 ENHR (European Network for Housing Research) Conference: "Mixité: an urban and housing issue?", 5-8 de julio, Toulouse (Francia). Disponible en http://www.enhr2011.com/sites/ default/files/Paper-LOPEZ_PUJADAS_BAYONA-WS12.pdf

Martí, M. \& Ródenas, C., (2006). Reinterpretando el crecimiento de la movilidad de España: la población extranjera y las migraciones repetidas. Cuadernos Aragoneses de Economía, 16(1), 37-59.

Méndez, R. (2001). Transformaciones económicas y reorganización territorial en la región metropolitana de Madrid. EURE, 27(80), 141-161. doi: http://dx.doi.org/10.4067/S025071612001008000007

Miralles-Guash, C. (2011). Dinámicas metropolitanas y tiempos de la movilidad. La Región metropolitana de Barcelona, como ejemplo. Anales de Geografia de la Universidad Complutense de Madrid (UCM, 31(1), 125-145. Disponible en http://revistas.ucm.es/index.php/AGUC/article/ view/36429/35290

Módenes, J. A. (1998). Flujos espaciales e itinerarios biográficos: la movilidad residencial en el área de Barcelona. Tesis Doctoral, Departamento de Geografía, Universitat Autónoma de Barcelona (UAB). Disponible en http://www.tdx.cat/handle/10803/4933

Módenes, J. A. \& López-Colás, J. (2004). Movilidad residencial, trabajo y vivienda en Europa. Scripta Nova, Revista Electrónica de Geografía y Ciencias Sociales, 8(159). Disponible en http://www. ub.edu/geocrit/sn/sn-159.htm

Mulder, C. H. \& Wagner, M. (1993). Migration and marriage in the life course: a method for studying synchronized events. European Journal of Population, 9(1), 55-76.

Nel.lo, O. (2011). Les dinàmiques territorials a la regió metropolitana de Barcelona (1986-2006). Hipòtesis interpretatives. Scripta Nova, Revista Electrónica de Geografia y Ciencias Sociales, 15(362). Disponible en http://www.ub.edu/geocrit/sn/sn-362.htm

Nogle, J. M. (1994). Internal migration for recent immigrants to Canada. International Migration Review, 28(1), 31-48.

Pandit, K. (1997a). Cohort and period effects in us migration: how demographic and economic cycles influence the migration schedule. Annals of the Association of American Geographers, 87(3), 439-450. Disponible en http://ludwig.missouri.edu/405/pandit.pdf 
Pandit, K. (1997b). Demographic cycle effects on migration timing and the delayed mobility phenomenon. Geographical Analysis, 29(3), 187-199. doi: 10.1111/j.1538-4632.1997. tb00956.x

Pozo, E. \& García-Palomares, J. C. (2009). Inmigración y cambio demográfico en la región metropolitana madrileña entre 1996 y 2006. Anales de Geografia de la Universidad Complutense de Madrid (UCM), 29(1), 111-138. Disponible en http://revistas.ucm.es/index. php/AGUC/article/view/AGUC0909120111A

Pujadas, I. (2009). Movilidad residencial y expansión urbana en la Región Metropolitana de Barcelona, 1982-2005. Scripta Nova, Revista Electrónica de Geografía y Ciencias Sociales, 13(290). Disponible en http://www.ub.edu/geocrit/sn/sn-290.htm

Pujadas, I. \& López-Villanueva, C. (2005). Hogares y cambios residenciales: la diferenciación espacial de los hogares en la Región Metropolitana de Barcelona, 1986-2001. Cuadernos Geográficos, 36, 409-435. Disponible en http://www.ugr.es/ cuadgeo/docs/articulos/036/036-025.pdf

Pumares, P.; García-Coll, A. \& Asensio, A. (2006). La movilidad laboral y geográfica de la población extranjera en España. Madrid: Ministerio del Trabajo y Asuntos Sociales.

Recaño, J. (2002). La movilidad geográfica de la población extranjera en España: un fenómeno emergente. Cuadernos de Geografia, 72, 135-156. Disponible en http://www.ced.uab.es/ publicacions/PapersPDF/Text217.pdf

Recaño, J. (2004). Migraciones internas y distribución espacial de la población española. En J. Leal (Coord.), Informe sobre la situación demográfica en España (pp. 187-230). Madrid: Fundación Abril Martorell.

Roca, J.; Arellano, B. \& Moix, M. (2011). Estructura urbana, policentrismo y "sprawl": los ejemplos de Madrid y Barcelona. Ciudad y Territorio, 43(168), 299-321.

Roca, J. \& Moix, M. (2005). The interaction value: Its scope and limits as an instrument for delimiting urban systems. Regional Studies, 39, 359-375.

Rossi, P. (1955). Why families move: a study of the social psychology of urban residential mobility. Glencoe, IL: The Free Press.

Smart, M. W. (1974). Labour market areas: uses and definitions. Progress in Planning, 2(4), 239-353.

Simon, P. (1998). Mobilité residentielle et milieu de vie des immigrés. En Y. Grafmeyer \& F. Dansereau

(Eds.), Trajectoires familiales et espaces de vie en milieu urbain (pp. 417-445). Lyon: Presses Universitaires de Lyon.

Trullén, J. \& Boix, R. (2003). Barcelona, metrópolis policéntrica en red. Working Paper 03/03, Economia Aplicada, Universitat Autónoma de Barcelona (UAB). Disponible en http://www. ecap.uab.es/RePEc/doc/wpdea0303.pdf

Van de Kaa, D. (1987). Europe's second demographic transition. Population Bulletin, 42(1), 1-59.

Van den Berg, L.; Drewett, R.; Klaasen, L. H.; Rossi, A. \& Vijverberg, C. H. T. (1982). Urban Europe. A study of growth and decline (Vol. 1). Oxford: Pergamon Press.

Vinuesa, J. (2009). La movilidad de la población y el desarrollo metropolitano de Madrid. En J. Hernández \& D. González (Eds.), Movilidad de la población y migraciones en áreas urbanas de España y Portugal (pp. 153-176). Santiago de Compostela: Universidade de Santiago de Compostela.

Xu, L. (2011). Inter-metropolitan migration of the newly landed immigrants in Canada: 1991-1996 and 1996-2001. Geojournal, 76, 501-524. 